\title{
Review
}

\section{Nuclear matrix, nuclear envelope and premature aging syndromes in a translational research perspective}

\author{
Pierre Cau ${ }^{a, b, c, *}$, Claire Navarro $^{a, b, 1}$, Karim Harhouri ${ }^{\mathrm{a}, \mathrm{b}, 1}{ }^{\text {, Patrice Roll }}{ }^{\mathrm{a}, \mathrm{b}, \mathrm{c}, 1,2}$, \\ Sabine Sigaudy a, a,d,1,3, Elise Kaspi ${ }^{\mathrm{a}, \mathrm{b}, \mathrm{c}, 1,2}$, Sophie Perrin ${ }^{\mathrm{a}, \mathrm{b}, 1}$, \\ Annachiara De Sandre-Giovannoli ${ }^{\mathrm{a}, \mathrm{b}, \mathrm{d}, 1,3}$, Nicolas Lévy ${ }^{\mathrm{a}, \mathrm{b}, \mathrm{d}, * *}$ \\ a Aix-Marseille Université, UMR_S 910, Génétique Médicale et Génomique Fonctionnelle, Faculté de Médecine, 27 Bd Jean Moulin, \\ 13385 Marseille Cedex 5, France \\ b INSERM, UMR_S 910, Génétique Médicale et Génomique Fonctionnelle, Faculté de Médecine, 27 Bd Jean Moulin, 13385 Marseille Cedex 5, France \\ c AP-HM, Service de Biologie Cellulaire, Hôpital La Timone, 264 Rue Saint Pierre, 13385 Marseille Cedex 5, France \\ d AP-HM, Département de Génétique Médicale, Hôpital d'enfants Timone, 264 Rue Saint Pierre, 13385 Marseille Cedex 5, France
}

\section{A B S T R A C T}

Lamin A-related progeroid syndromes are genetically determined, extremely rare and severe. In the past ten years, our knowledge and perspectives for these diseases has widely progressed, through the progressive dissection of their pathophysiological mechanisms leading to precocious and accelerated aging, from the genes mutations discovery until therapeutic trials in affected children.

A-type lamins are major actors in several structural and functional activities at the nuclear periphery, as they are major components of the nuclear lamina. However, while this is usually poorly considered, they also play a key role within the rest of the nucleoplasm, whose defects are related to cell senescence. Although nuclear shape and nuclear envelope deformities are obvious and visible events, nuclear matrix disorganization and abnormal composition certainly represent the most important causes of cell defects with dramatic pathological consequences. Therefore, lamin-associated diseases should be better referred as laminopathies instead of envelopathies, this later being too restrictive, considering neither the key structural and functional roles of soluble lamins in the entire nucleoplasm, nor the nuclear matrix contribution to the pathophysiology of lamin-associated disorders and in particular in defective lamin A processing-associated aging diseases.

Based on both our understanding of pathophysiological mechanisms and the biological and clinical consequences of progeria and related diseases, therapeutic trials have been conducted in patients and were terminated less than 10 years after the gene discovery, a quite fast issue for a genetic disease. Pharmacological drugs have been repurposed and used to decrease the toxicity of the accumulated, unprocessed and truncated prelaminA in progeria. To date, none of them may be considered as a cure for progeria and these clinical strategies were essentially designed toward reducing a subset of the most dramatic and morbid features associated to progeria. New therapeutic strategies under study, in particular targeting the protein expression pathway at the mRNA level, have shown a remarkable efficacy both in vitro in cells and in vivo in mice models. Strategies intending to clear the toxic accumulated proteins from the nucleus are also under evaluation. However, although exceedingly rare, improving our knowledge of genetic progeroid syndromes and searching for innovative and efficient therapies in these syndromes is of paramount importance as, even before they can be used to save lives, they may significantly (i) expand the affected childrens' lifespan and preserve their quality of life; (ii) improve our understanding

\footnotetext{
* Corresponding author at: INSERM, UMR_S 910, Aix Marseille Université, Faculté de Médecine, 27 Bd Jean Moulin, 13385 Marseille Cedex 5, France. Tel.: +3304913243 01/04913882 10; fax: +33049179 72 27/0491384676.

** Corresponding author at: INSERM, UMR_S 910, Aix Marseille Université, Faculté de Médecine, 27 Bd Jean Moulin, 13385 Marseille Cedex 5, France. Tel.: +3304913243 01/04913877 87; fax: +3304917972 27/0491384676.

E-mail addresses: pierre.cau@univ-amu.fr (P. Cau), nicolas.levy@univ-amu.fr (N. Lévy).

1 Tel.: +330491324301; fax: +3304917972 27

2 Tel.: +33 04913882 10; fax: +33 0491384676 .

3 Tel.: +33 04913877 87; fax: +330491384676.
} 


\section{Contents}

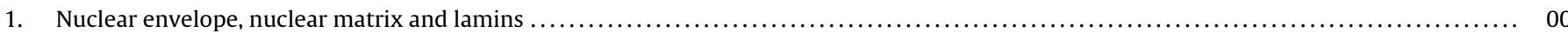

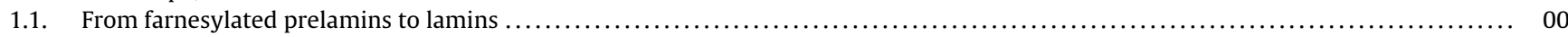

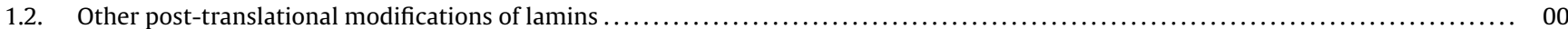

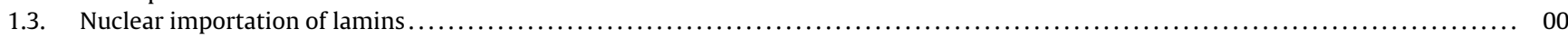

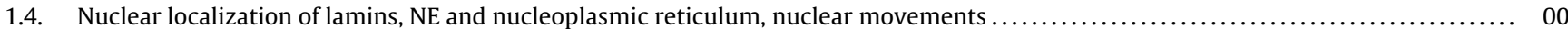

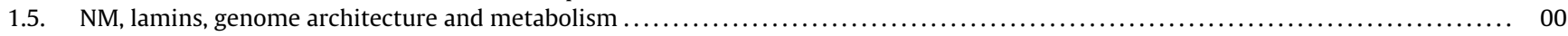

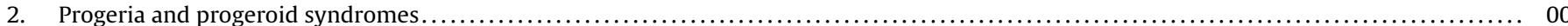

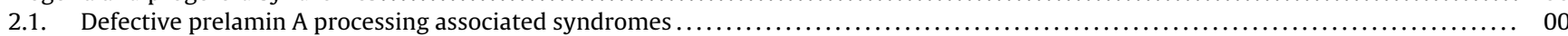

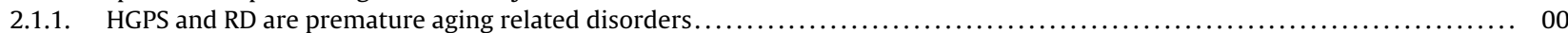

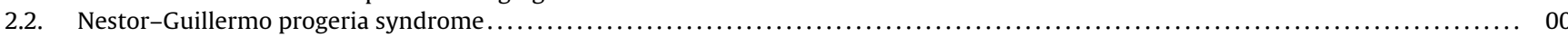

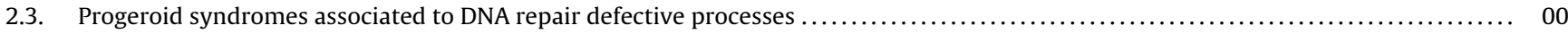

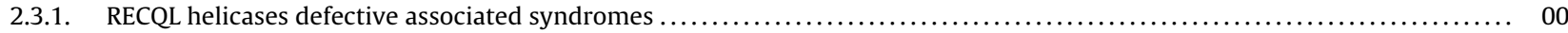

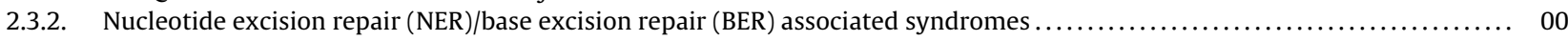

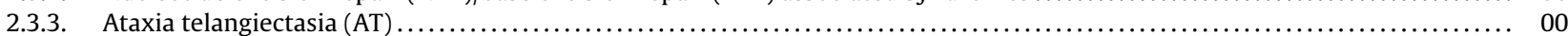

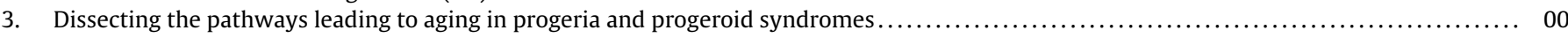

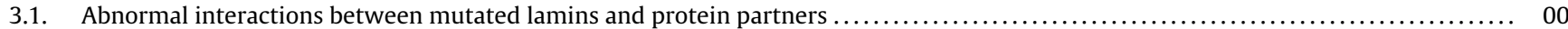

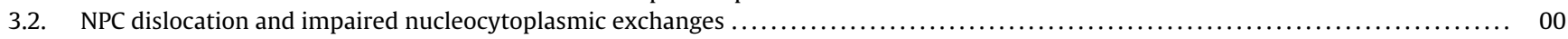

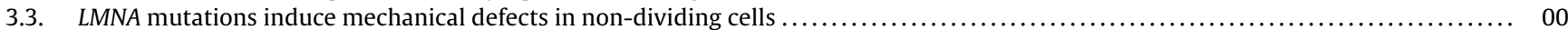

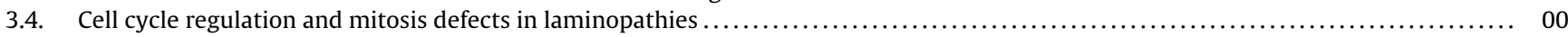

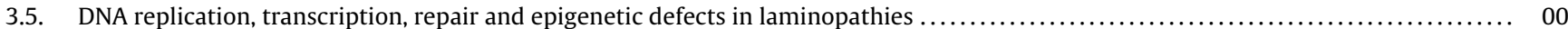

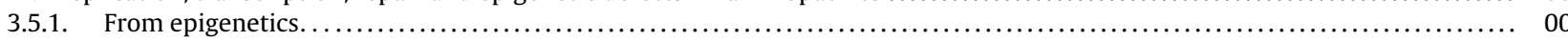

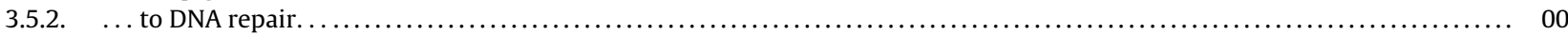

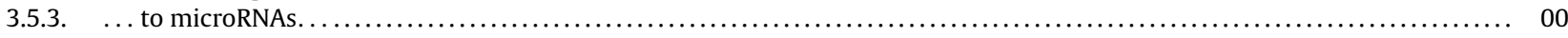

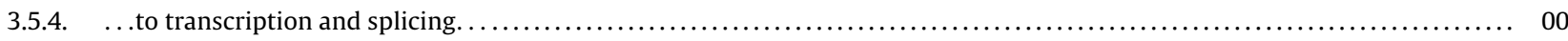

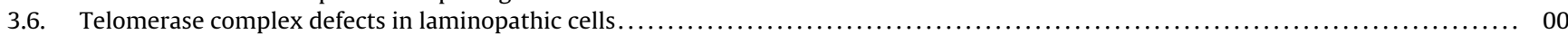

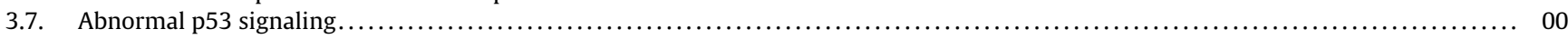

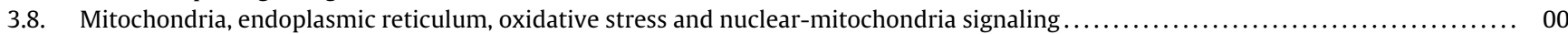

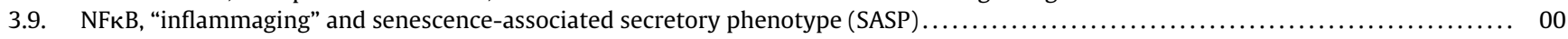

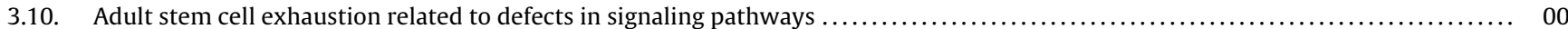

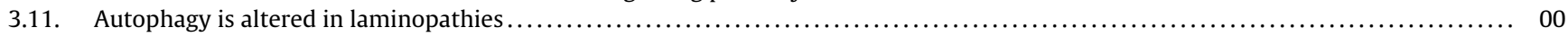

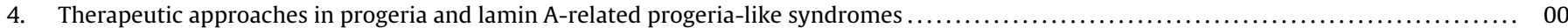

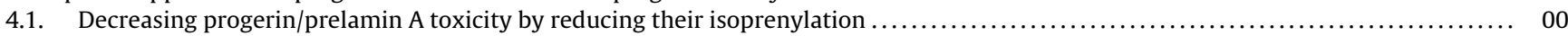

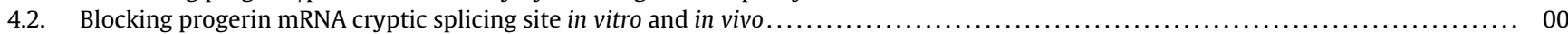

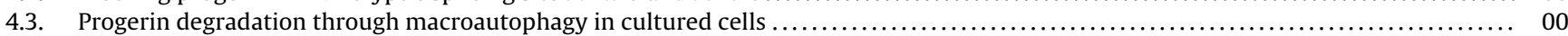

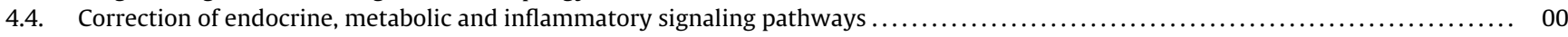

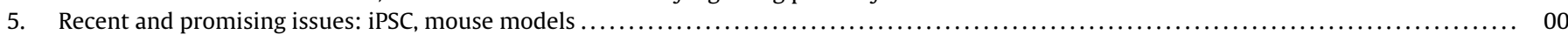

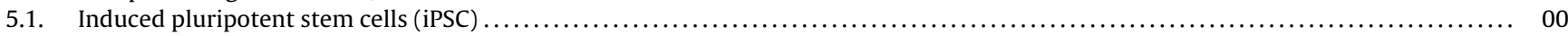

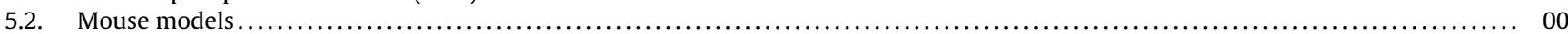

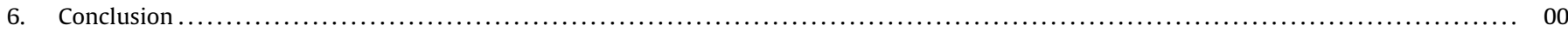

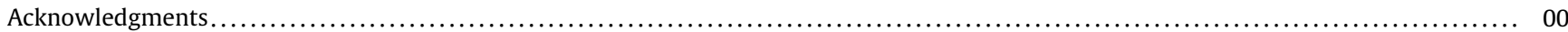

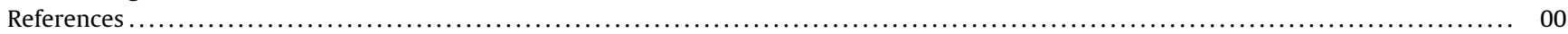

\section{Nuclear envelope, nuclear matrix and lamins}

In eukaryotic cells, nuclear genome is packed in the form of the highly organized chromatin within nucleoplasm, delineated by the nuclear envelope (NE). The NE is a specialized cisterna of endoplasmic reticulum (ER), separating nuclear from cytoplasmic compartments and made of two distinct membrane domains only interconnected through nuclear pore complexes (NPC) $[1,2]$. The outer nuclear membrane (ONM) exhibits several membrane and luminal ER characteristics as well as functions (from ribosome-linked synthesis to post-traductional processing of proteins...). The inner nuclear membrane (INM) harbors an unique set of about 80 transmembrane proteins (NPC proteins being excluded), that are synthetized by and inserted into ER or ONM, and reach INM after crossing NPC [3].
Less than 10 of these INM proteins are well characterized because they are yet known to be involved in human genetic diseases [4]. However the great majority of INM transmembrane proteins, most of them discovered through proteomic studies, remain still uncharacterized, even if they could be good candidates for yet unidentified human diseases [5]. Moreover, the expression of some of these INM proteins is cell- or tissue-specific [6-10]. Therefore, these INM proteins could contribute to the phenotype variability exhibited by patients harboring a mutation in the gene encoding an interactor of these INM proteins.

Besides nuclear genome and all the enzymatic and nonenzymatic machinery required for nuclear genome functions, the nucleoplasm also contains a protein network called nuclear matrix (NM) [11], whose peripheral region, known as nuclear lamina, interacts with INM proteins, NPC nucleoplasmic domain and peripheral chromatin [12]. 
Removing in a sequential fashion "soluble" proteins, NE lipids and chromatin components leaves behind about 400 NM proteins being characterized by proteomics methods [13-15]. Besides lamins [16], NM contains other scaffolding proteins such as Nuclear Mitotic Apparatus protein (NuMA) [17], actin and several actin-binding proteins [18-22] and less-known matrins [23] or matrin-domain containing proteins $[24,25]$.

\subsection{From farnesylated prelamins to lamins}

Lamins are type $\mathrm{V}$ intermediate filaments divided into $\mathrm{A}$ and $B$ types. In mammals, the two major A-type lamins (lamin A and C), the minor isoforms lamin A $\Delta 10$ and the lamin C2, the later expressed in germ cells (as well as in cultured C2C12 differentiating myoblasts [26]) are derived from the same gene (LMNA) by alternative splicing [27]. B-type lamins are encoded by two different genes, lamin B1 by LMNB1, lamins B2 and germ cell-specific lamin B3 by LMNB2 [28].

Lamins A, B1 and B2 are first expressed as cytosolic precursors, prelamins, that undergo extensive post-translational processing involving their C-terminal CAAX box. The first three steps are common to A- and B-type prelamins. The C-terminal cysteine is farnesylated by farnesyltransferase. The 15-carbon hydrophobic farnesyl group facilitates the prelamin insertion and anchoring into the cytosolic leaflet of ER membrane (or of the ONM), thus allowing the further processing steps performed by specific ER (or ONM) enzymes, their active site facing cytosol. The AAX motif is then clipped off by one of two proteases, FACE1/ZMPSTE24 or FACE2/Rce1. The third step is the carboxymethylation of the cysteine residue by the isoprenyl-cysteine-carboxy-methyltransferase (ICMT). The processing of B-type lamins terminates at this third step, leading to the permanent farnesylation and carboxymethylation of mature B-type lamins. Prelamin A undergoes a fourth last proteolytic cleavage by FACE1/ZMPSTE24 removing the 15 C-terminal aminoacids, including the farnesylated carboxymethylated cysteine residue, to form mature lamin A [28] (Fig. 1A and B).

Since its mRNA is produced through alternative splicing in $L M N A$ exon 10, lamin $C$ is directly synthetized as mature form that lacks the $98 \mathrm{C}$-terminal aminoacids present in prelamin A and the CAAX box, encoded by LMNA exon 12 . Lamin C2 lacks the first 112 residues of lamin C. Lamin C2 N-terminus (MGNAEGR) is encoded by exon 1C2 located in LMNA intron 1 [29]. Contrasting with lamins $A$ and C, lamin C2 is myristoylated on its N-terminal glycine, this lipid group anchoring the protein into discrete plaques resulting in a discontinuous labeling of germ cell INM $[30,31]$.

\subsection{Other post-translational modifications of lamins}

Besides acylation, lamins undergo other modifications [32,33], whose analysis has been improved through mass spectrometry (and SILAC) experiments.

In nuclei of intima and media cells from large elastic arteries, A-type lamins are target for advanced glycation end-products, a phenomenon probably involved in enhanced vascular dysfunction and atherosclerosis exhibited by diabetic patients [34]. O-glycosylation of A-type lamins on at least 4 serine or threonine residues [35-37] could interfere with lamin polymerization as already seen for other intermediate filaments [38] and has been shown to vary during cell cycle [39].

Phosphorylation of lamins and their partners has been shown to be important for NE breakdown at the beginning of mitosis $[40,41]$. Two serine residues of lamin A and C are substrates for AKT kinase, activated by several signaling pathways [42], the phosphorylation of serine 404 leading to prelamin A autophagic degradation [43]. As several other nuclear proteins such as histones, A- and

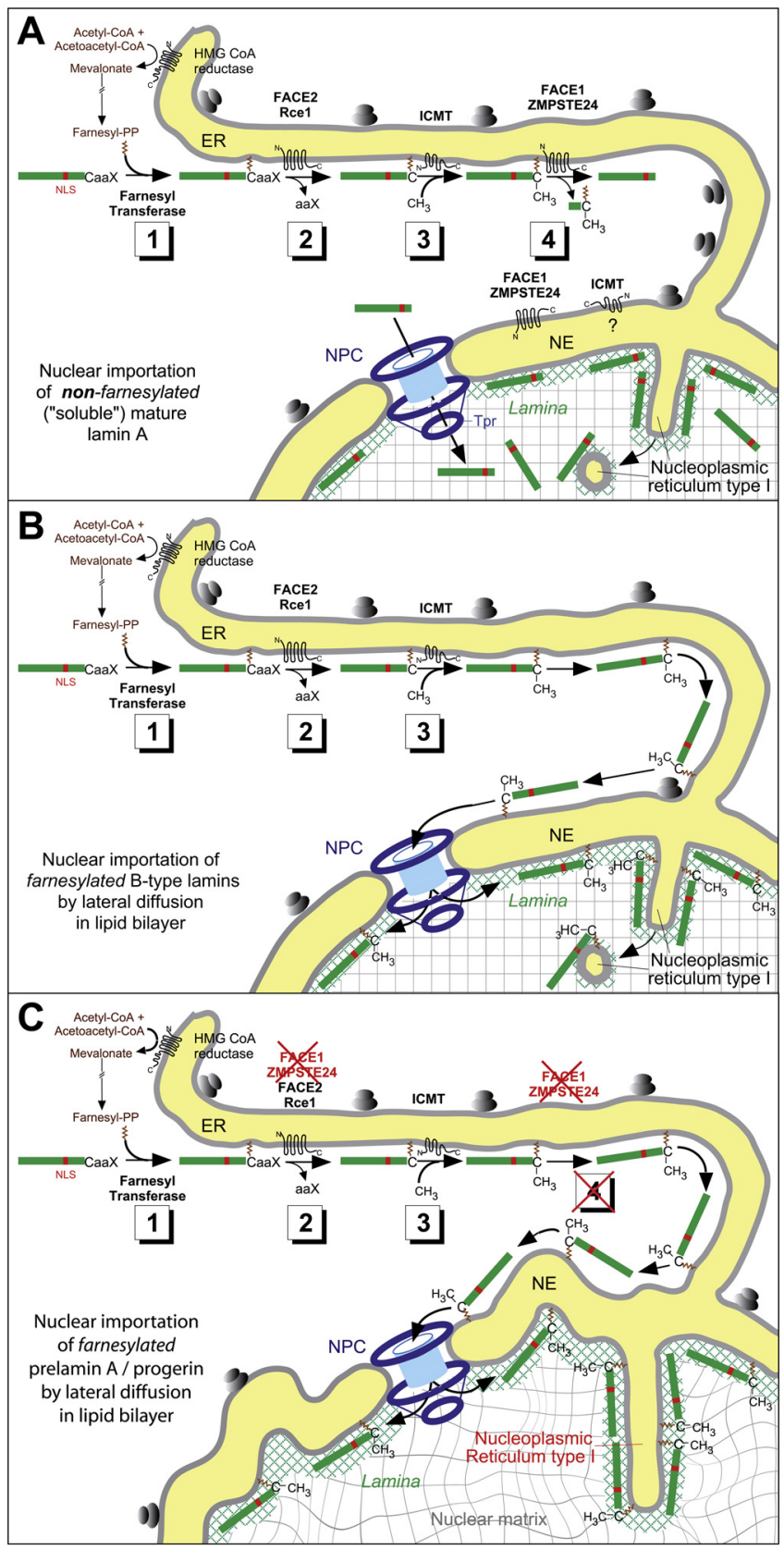

Fig. 1. Post-translational processing of A- and B-type prelamins. (A) Processing of prelamin $A$ in four steps and nuclar import of lamin $A$. The nuclear importation through nuclear pore complex (NPC) of mature lamin A as a "soluble protein". The interactions of prelamin A with INM protein before their nuclear importation are not described. NLS, nuclear localization signal; Tpr, nucleoporin of the nucleoplasmic basket, (B) processing in three steps of B-type prelamins and nuclar import of B-type lamins. As they keep their farnesyl moiety, B-type lamins remain anchored to membrane bilayers. After their nuclear importation, B-type lamins are anchored to the INM and the IMN extensions toward nucloplasm, called nucleoplasmic reticulum type I, and (C) processing in three steps and nuclar import of progerin (HGPS) or farnesylated prelamin A (RD). While FACE1/ZMPSTE24 cannot cleave progerin (HPGS) or because the protease is absent or inactive (RD), progerin and prelamin A keep their farnesyl moiety, and remain anchored to membrane bilayers. After nuclear importation, progerin and farnesylated prelamin A stay anchored to the INM and to the IMN extensions toward nucloplasm, called nucleoplasmic reticulum type I. The increase in the amount of NE-bound A-type lamins results in the increase of NE surface area leading to nuclear shape deformations and to the expansion of nucleoplasmic reticulum from INM. 
B-type lamins have been shown to be acetylated on lysine residues [44], although the role of this modification remains unclear. During C2C12 myoblast fusion, lamin C2 has been shown to be dimethylated on arginin residues [26].

The nucleus contains all the enzymatic machinery involved in regulating the fate of nuclear proteins through their balanced ubiquitylation-deubiquitylation [45-47] and symoylation-desumoylation modifications [48-50]. Lamin A could be ubiquitylated on 25 lysine residues and targeted to proteasomal degradation [51], as shown for wild-type and $\Delta K 32$ Lmna in mouse cardiomyocytes [52]. Various laminopathies activate several ubiquitin-ligases and increase proteasomal degradation of proteins within nucleus [53]. For example, the proteasomal degradation of ATR kinase within nucleus results in DNA repair defects [54].

Several mass spectrometry experiments evidenced that A- and B-type lamins can undergo sumoylation, another covalent and reversible lysine modification [55-57]. Binding of SUMO1 leads to mono-sumoylation, whereas binding of SUMO2 and SUMO3 results in chains of 4-7 molecules in length, the last one being SUMO1 $[58,59]$. Lamin A sumoylation is modified by several pathogenic mutations targeting lysines or residues close to sumoylation consensus sequences [60-63].

\subsection{Nuclear importation of lamins}

Even if A- and B-type lamins bear a nuclear localization signal (NLS) in their tail domain [64], the nuclear importation mechanism could be different between farnesylated B-type lamins, anchored to membranes, and lamins A and C produced as "soluble" proteins lacking this farnesyl anchor. However, several data reported that $A$ and $C$ lamins interact, before lamin nuclear importation, with ER-synthetized membrane proteins and with the same membrane proteins, after their insertion into INM. In human cell lines displaying abnormal expression and/or localization of lamins $A$ and $C$, the lack of lamins $A$ and $C$ from the nuclear envelope was correlated with emerin mislocalization in the ER [65]. In $\mathrm{Lmna}^{-/-}$cells, emerin is not imported into INM and stays mislocalized in ER membrane [66].

INM proteins, synthetized by ribosomes bound to ER or to ONM, interact with the specialized importin- $\alpha-16$ that recognizes INM sorting signal. Importin- $\alpha$-16-INM protein complexes slide along ER membrane and ONM, cross NPC to reach their INM final localization $[67,68]$. The same sliding mechanism probably allows the nuclear importation of lamins bound to membranes through their farnesyl anchor, either B-type lamins or farnesylated prelamin A or progerin produced in Hutchinson-Gilford progeria syndrome (HGPS), restrictive dermopathy (RD) (see below) or experimentally after mutation in the FACE1/ZMPSTE24 cleavage site of prelamin A.

\subsection{Nuclear localization of lamins, NE and nucleoplasmic reticulum, nuclear movements}

The presence or the lack of the farnesyl group influences the nucleoplasmic localization of lamins. Farnesylated B-type lamins are anchored to INM in the nuclear lamina only. Lamins A and C are localized in nuclear lamina, where they interact together [16], with B-type lamins [69] and with several INM and NPC proteins [70-72].

Lamins $A$ and $C$ also are components of the NM distributed throughout the nucleoplasm $[32,73]$. Time lapse imaging confirmed the high mobility of lamins $A$ and $C$ within nucleoplasm, contrasting with the lower mobility, within nuclear lamina, of lamins A, C and B, the later being anchored to INM through its farnesyl group [74,75].

However, B-type lamins can also be detected at a distance from nuclear lamina in the perinucleolar nucleoplasm [76], and anchored to the membrane of the nucleoplasmic reticulum (NR) membrane (Fig. 1B). This dynamic structure [77,78] fall into two main classes depending on whether the ONM is involved [79]. Type I NR are finger-like expansions into nucleoplasm of the INM only, whereas type II NR involves the invagination of both INM and ONM, including a portion of cytosol and sometimes cell organelles. NR development can be induced by increasing the amount of isoprenylated nuclear proteins [80-84], and was also observed in genetic diseases resulting from prelamin A processing defects [85] (Fig. 1C).

Videomicroscopy evidenced another surprising phenomenon. The entire nucleoplasmic content has been shown to spin in zebrafish embryos [86], and in cultured cells, either migrating fibroblasts [87,88] or developing myotubes [89]. Nucleus rotation affects INM, ONM and their proteins and involves microtubules (MT), dynein and kinesin, whereas centrosome remains stable. MT and their motor microtubule-associated proteins (MAP), that are known to be involved in NE breakdown during mitosis and meiosis [90], also play a role, during interphase, in the folding of NE and in the development of type II NR [91].

The LINC (LInks the Nucleoskeleton and Cytoskeleton) complexes connect the chromatin and the nuclear lamina across the $\mathrm{NE}$ with the three components of the cytosolic cytoskeleton, actin microfilaments, microtubules, intermediate filaments and their associated proteins [92].

Nuclear movements can be observed in cultured cells linked to interactions between ONM and LINC complex proteins with cytosolic microtubules and motor MAPs [93] or between emerin, located in ONM [94,95] with actin cytoskeleton and myosins [96].

The migration of neurons during development involves saltatory movements of neuronal cell body and nucleus in the direction of migration. Neuronal migration offers another example of the collaboration between, on one hand, actin microfilaments and type II myosin and, on the other hand, of microtubules, dynein [97] and other centrosome-associated proteins such as Lis1 and DCX, all partners involved in various neuronal migration genetic disorders [98]. Lamin B2-deficient mice present severe brain abnormalities resembling lissencephaly, abnormal layering of neurons in the cerebral cortex and cerebellum, demonstrating that lamin B2 plays an essential role in neuronal migration and brain development [99].

B-type lamins could have unexpected extranuclear functions. Lamin B2 mRNAs are present in axons of Xenopus retinal ganglion cells and are translated into protein. Axonal lamin B2 associates with mitochondria, while lamin B2-deficient axons exhibit defects in mitochondrial function, shape and mobility, and in axon morphology, thus suggesting that lamin B2 synthetized into axons plays a major role in axon maintenance through promoting mitochondrial function [100].

\subsection{NM, lamins, genome architecture and metabolism}

Besides providing a structural framework to nucleoplasm, peripheral and nucleoplasmic lamins [28,101] together with their interacting partners [70] and the other NM components [14,102-104] play important roles in epigenetics, chromatin organization, DNA replication and repair, transcription, and their dynamics. DNA replication takes place in a fixed number of sites liked to NM [105]. RNA elongation and processing factories, known to be associated with NM [106] associate RNA polymerases, matrin 3 and A- and B-type lamins [107,108]. A- and B-type lamins are involved in DNA repair [109-111]. Matrin 3 interacts with the nuclear DNA damage response and repair machinery [112]. NuMA is required for the selective induction of p53 target genes $[113,114]$. A variety of genome-wide mapping techniques result in a picture of interphase chromosome, integrating both their linear segmentation into several domains, exhibiting different protein compositions, and their non-random three-dimensional organization allowing many local and long-range contacts among genes 
and other sequence elements [115]. Chromatin dynamics add a fourth dimension to this picture [116]. Within nucleoplasm, dynamic arrangements of the $10 \mathrm{~nm}$ chromatin fiber form several loops anchored to NM [117,118], that bring closer intra- and inter-chromosomal domains, called transcription factories, to the same nucleoplasmic location [119], whose organization and regulation are controlled by sequence-specific DNA-binding protein CTCF (CCCTC-binding factor) and the multiprotein cohesin complex [120]. The loops associate co-activated or co-repressed genes and control interactions between regulatory sequences and their target genes [121]. This dynamic genome topology is also observed during DNA replication [122] and play an important role in development, differentiation and aging [123].

Lamins, NM components, INM and NPC proteins also contribute to the definition of chromosome territories [115,124], where nuclear lamina-associated domains are different in terms of gene composition and activity from the domains of the same chromosome facing the nucleoplasm center and emitting chromatin loops [125-127]. In metazoan cells, NE, lamina and peripheral heterochromatin exhibit complex dynamic relationships, involving the peripheral retention of inactive genes and their release to the more central nucleoplasm [128]. Spatio-temporal changes in lamina composition underlie both differentiation- and cell typespecific chromatin organization and genome function [129]. Finally, nuclear dynamic mechanical architecture and functions result from bidirectional interactions between lamins, NM and NE proteins, cytoskeleton, plasma membrane, extracellular matrix components and their plasma membrane receptors [130-132], controlling at least some aspects of nuclear genome metabolism, cell differentiation and development $[133,134]$.

All these cell components and mechanistic aspects should be considered when exploring pathophysiological mechanisms associated to lamin/prelamin associated disorders.

\section{Progeria and progeroid syndromes}

Progeroid syndromes are heritable human disorders including clinical symptoms that remind aging but appearing prematurely and whose evolution is dramatically accelerated. In these syndromes, premature aging is defined as "segmental" since only some of the aging features are accelerated. Most human syndromes of accelerated aging are caused by one of two major mechanisms: defects in DNA repair systems and alterations in the nuclear lamina and matrix proteins. Meanwhile, many nosological entities that include partial or systemic symptoms related to aging still remain of unidentified mechanism.

Clinical and physiological changes that are observed in the natural course of aging are never totally recapitulated in one or another independant progeroid syndrome. However, after years of studying senescence, aging and progeroid syndromes, it becomes evident that most of the mechanisms identified as the basis of segmental progeroid disorders are also part of mechanisms underlying physiological aging. In this context, Werner syndrome (WS) (OMIM 277700) and Hutchinson-Gilford progeria syndrome (HGPS) (OMIM 176670) have been the most extensively studied, as they are closely reminiscent of natural clinical aging. Pathophysiologically, the known progeroid syndromes are mostly caused, either by mutations in genes encoding DNA repair proteins, such as in WS, Bloom syndrome (BS), Rothmund-Thomson syndrome (RTS), Cockayne syndrome (CS) syndrome, Xeroderma pigmentosum (XP) [135-140]; or by mutations in genes encoding A-type lamins or partners involved in their biological cascade, such as HGPS [141,142], restrictive dermopathy (RD) $[143,144]$ or the more recently identified Nestor-Guillermo syndrome [145]. However, in premature aging animal models, other pathways have shown to be affected such as mitochondrial or TP53 [146,147]. This is of importance, as the cause of premature aging syndromes, namely Hallerman Streiff (OMIM 234100), Wiedeman Rautenstrauch (OMIM 264090), and others still remain to be elucidated (Fig. 2).

A number of cellular and physiological pathways have been linked to aging, including regulation of the insulin/growth hormone axis, pathways involving ROS metabolism, caloric restriction, and DNA repair. Living models, ranging from yeast, to nematodes, mice and rats, have been instrumental in obtaining evidence for these connections $[148,149]$.

\subsection{Defective prelamin A processing associated syndromes}

In 2003, we and others identified mutations in the LMNA gene as causing HGPS, one of the most paradigmatic segmental aging diseases $[141,142]$. This discovery revealed an unexpected role of lamins and more generally of the nuclear matrix composition and organization, in premature aging disorders. This also allowed entering into a translational era in the context of progeria and related disorders, leading to the characterization of previously unexplored diseases, identification of mechanisms, and the development of proofs of concept toward therapies (Fig. 3). This also raised the crucial question of potential links between nuclear lamina, nuclear envelope and matrix-associated proteins with natural aging, while progerin, the resulting product of HGPS-related LMNA mutation, is produced by Ductus arteriosus cells at birth [150] and in several other cell types during physiological aging [151-153].

\subsubsection{HGPS and RD are premature aging related disorders}

Since its first clinical description by Hutchinson in 1886, followed by the clinical report by Gilford in 1897, progeria was a fascinating disorder for clinicians and scientists, due to the apparent clinical recapitulation of normal aging, although the similarities are only partial and evolve in the context of a developmental disorder. Following the discovery of the major mutation in LMNA causing HGPS in 2003 [141,142], FACE1/ZMPSTE24 mutations have been identified that caused Mandibulo-Acral dysplasia (MAD) [154] another classified progeroid disease, progeria in a very small subset of patients and RD when both alleles exhibit a null mutation $[143,144]$. These observations provided clues to the search into the pathophysiology of HGPS and other premature aging disorders related to lamins $\mathrm{A} / \mathrm{C}$ and allowed to identify an abnormal persistence of a farnesylated motif at the $C$ terminal end of misprocessed prelamin $\mathrm{A}$ as a major mechanism underlying these disorders (Fig. 1C). This was the basis for designing pre-clinical proofs of therapeutic principles toward including patients in early phases of clinical trials using molecules inhibiting the transfert or the biosynthesis of farnesyl groups (see below Section 4.1).

2.1.1.1. Hutchinson-Gilford progeria syndrome. Progeria is an extremely rare, severe and uniformly fatal developmental disorder characterized by precocious onset of pathologies which are typical of advanced age (Fig. 2). The clinical phenotype is characterized by severe growth retardation, usually associated to skeletal alterations (osteolyses, osteoporosis), marked amyotrophy, lipodystrophy, skin atrophy and alopecia [155-157]. These symptoms usually appear after the first year of life, most of the children being healthy at birth. The mean age at diagnosis is 2.9 years, generally following a fall-off from the growth curves, loss of scalp hair (40\%), scleroderma-like focal changes (28\%), lipodystrophy (20\%), and the appearance of characteristic facial dysmorphic traits, including a characteristic visible vein across the nasal bridge [155]. The mean final height of HGPS children is about $110 \mathrm{~cm}$, the mean final weight $14.5 \mathrm{~kg}$, children linearly gaining a mean of $0.440 \mathrm{~kg} /$ year from the second year of age [158]. 


\begin{tabular}{ll}
\multicolumn{1}{c}{ Phenotype } & $\begin{array}{c}\text { Gene } \\
\text { Mutation } \\
\text { [reference] }\end{array}$ \\
\hline $\begin{array}{l}\text { Deficient prelamin A processing } \\
\text { Hutchinson-Gilford Progeria syndrome (HGPS) - progerin } \\
\text { - growth retardation }\end{array}$ & LMNA \\
- pinched nose & - micrognathia \\
- alopecia / sparse hair & - osteolysis of distal phalanges, clavicles \\
- osteopenia & - subcutaneous lipoatrophy \\
- abnormal skin pigmentation & dominant, de novo \\
- major arteriosclerotic disease & OMIM 176670
\end{tabular}

Restrictive dermopathy (RD) ) - prelamin A

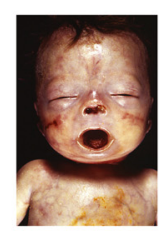

- intrauterine growth retardation

- open "O" mouth

ZMPSTE24

- micrognathia

- thin, tight translucent skin with erosion

at flexure sites

- sclerodermatous lesions

- pulmonary hypoplasia

- osteolysis of distal phalanges, clavicles

(two null mutations)

OMIM 275210

[141] [142]

LMNA

c. $1583 \mathrm{C}>\mathrm{T}$, p. T528M

and

c.1619T>C, p.M540T

[180]

- osteopenia

- lipodystrophy

Nestor-Guillermo Progeria Syndrome (NGPS)

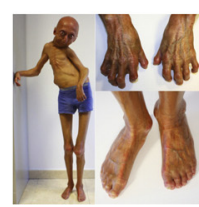

- growth retardation,

- generalized lipoatrophy

- dry atrophic skin with pigmentation defects

- severe osteoporosis, osteolysis

- major skeletal deformations

- micrognathia

- prominent subcutaneous venous patterning

\section{BANF1}

c.34G $>$ A, p.A12T

homozygous

OMIM 614008

[143] [181]

Hallermann-Streiff Syndrome (HSS)

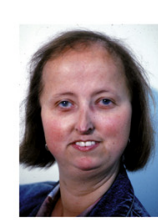

- brachycephaly with frontal bossing

- hypotrichosis

- cataracts and microphtalmia

- beaked nose

- micrognathia

- skin atrophy

- dental anomalies

- short stature

\section{Unknown gene}

OMIM 234100

Hennekam R.C.M, courtesy

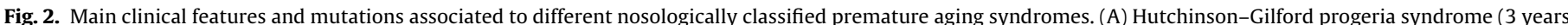

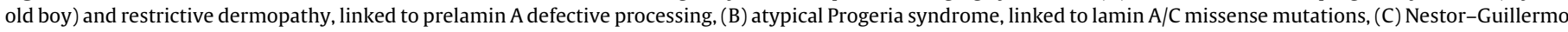

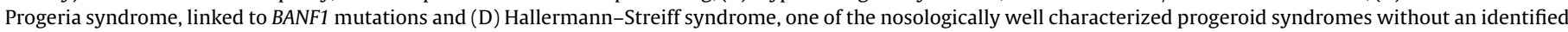
genetic origin.

Typical facial dysmorphism includes micrognathia, prominent scalp veins, alopecia and a beaked nose. A high pitched voice is common. At the bone level, patients present with clavicular hypoplasia, acro-osteolyses of distal phalanges and generalized osteopenia. Hyperpigmented lesions or hyperplastic scars can be observed $[159,160]$. Sweat glands and sebaceous glands are reduced in number and subcutaneous adipose tissue is atrophic [161]. Tooth eruption is delayed and dental crowding is often observed. The cardiovascular system is severely affected, with small diameter of the intima and media and major loss of vascular smooth muscle cells with fibrous replacement (reviewed in [162]). These data suggest that the pathophysiology underlying HGPS vascular lesions is somewhat different from that of physiological age-related atherosclerotic lesions since typical plaque formation is usually not observed $[163,164]$. Strokes are frequent, at a median age of 9 years and myocardial infarction is the most frequent cause of death, at a mean age of 13.5 years. Enlargement of the left ventricle is observed in most patients and valves are often calcified. Cognitive functions are fully preserved in progeria as well as cancer incidence is not increased. These observations must however be taken with caution and be regarded with the early age at death.

Finally, it is of importance to note that, in our experience, progeria is a painful disease, mainly of bone or muscle origin (Sigaudy, Levy et al., unpublished). The incidence of progeria remains unknown while estimated to $1 / 4$ to $8 \times 10^{-6}$ births, with a balanced sex-ratio. 


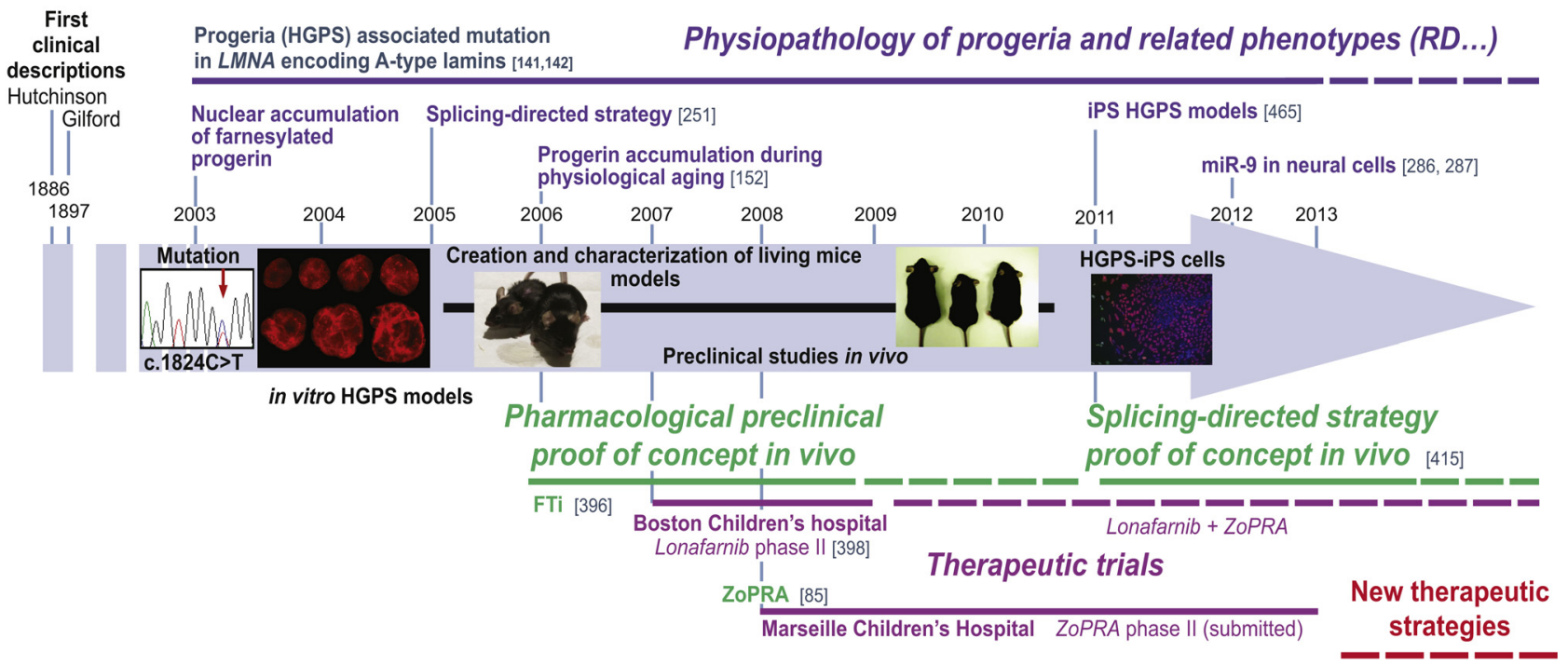

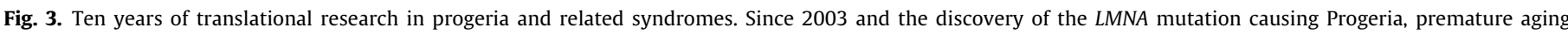

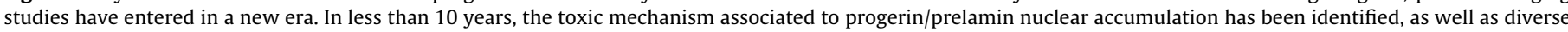

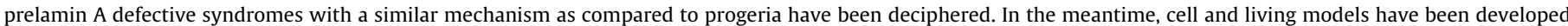

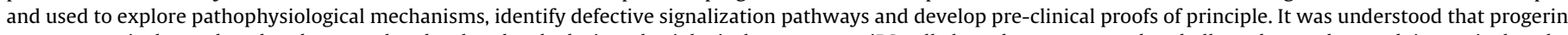

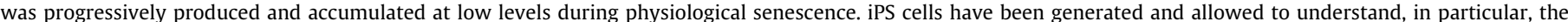

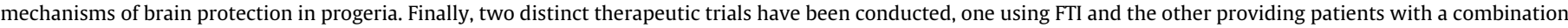
of statins and amino-bisphosphonates.

HGPS is caused by a de novo point mutation in LMNA exon 11 (c.1824 C>T; p.G608G) activating a cryptic donor splice site in LMNA exon 11 leading to so-called progerin, that is characterized by the deletion of 50 amino-acids including the cleavage site of the processing FACE1/ZMPSTE24 endoprotease and leading to the abnormal persistence of a farnesylated cystein at the prelamin C-terminal end [141,142].

2.1.1.2. Restrictive dermopathy (RD). In 2003, Agarwal et al. observed for the first time the involvement of FACE1/ZMPSTE24 in severe mandibuloacral dysplasia (MAD-B), a relatively mild progeroid syndrome [154]. This followed the report by Novelli et al. in 2002 of LMNA homozygous mutations in MAD-A [165].

Following these reports, RD, a perinatal lethal genodermatosis, was linked to primary or secondary lamin A dysfunction [143,144]. $\mathrm{RD}$ is characterized by a severe intrauterine growth delay, generalized arthrogryposis, tight, stiff, translucent skin which is frequently eroded on flexure sites. Clavicules are hypoplasic and bone density is reduced, with fontanel enlargement. Facial dysmorphy includes a small pinched nose, the mouth open in a fixed "O" position, retromicrognathia, and variable loss of scalp hair, eyebrows and eyelashes [166-168] (Fig. 2). Histologically, the skin shows hyperkeratosis, a thin dermis, abnormally dense collagen bundles, with almost completely absent elastic fibers. Patients' death results in most cases from respiratory failure $[169,170]$. Most patients affected with RD carry homozygous or compound heterozygous null mutations in ZMPSTE24 [171] while a very small subset of RD cases are associated to splicing mutations in LMNA with similar pathophysiological consequences as compared to HGPS [144]. These observations raised the concept of prelamin A-deficient processing associated syndromes, being a clinical continuum of apparently heterogeneous disorders, whose the disease evolution and severity depends the dose of accumulated farnesylated mis-processed prelamin A $[144,171,172]$.

2.1.1.3. Other lamin-linked premature aging syndromes. In addition to these two clinically well characterized syndromes, overlapping HGPS/MAD sometimes or RD/HGPS syndromes were associated with several LMNA mutations in exon 11. All mutations reported lead to variable expression levels of progerin or other truncated prelamin A farnesylated isoforms, respecting the rule: low amounts of truncated farnesylated isoformes are associated with milder phenotypes, such as patients carrying LMNA c. $1968 \mathrm{G}>$ A or c. $1968+5$ G>A diagnosed as "Werner syndrome like" for whom progerin was detected in lower level compared to classical HGPS [173,174]. A 45 year-old patient was reported carrying an atypical mutation in exon 11, c. $1868 \mathrm{C}>\mathrm{G}$, that led to another truncated farnesylated isoform named lamin $\Delta 35$. The same mutation was observed in a young patient presenting with a progeria-like syndrome and an osteosarcoma [175]. Conversely, higher amounts of truncated isoforms are associated with extremely severe syndromes in which the premature death occurs from the first months to the first year of life [176]. Given their common molecular bases linked to prelamin Adeficient processing, we propose to name this group of diseases "HGPS-like" syndromes. Conversely, a distinct group of premature aging syndromes called "Atypical Progeria Syndromes" (APS) are being delineated [177-179] (Fig. 2). They are characterized by prelamin A-proficient processing and are due to the production of A-type lamins carrying specific missense mutations. They can be transmitted on a dominant or a recessive pattern of inheritance (see [177] for a recent review).

\subsection{Nestor-Guillermo progeria syndrome}

In 2011, a novel syndrome including several of the clinical signs observed in progeria was reported and named Nestor-Guillermo progeria syndrome (NGPS) [180]. NGPS has been defined as a chronic progeria because of its slow clinical course and relatively long survival, despite its early onset. NGPS clinical findings differ from classical HGPS in several aspects. Remarkably, in NGPS, growth is less retarded than in HGPS and lifespan is longer. A severe osteolysis in all affected bones (mandible, clavicles, ribs, distal phalanges, and long bones) as well as the absence of atherosclerosis, cardiac ischemia, arterial hypertension, or cerebral vascular disease, are marked differences when comparing the two reported patients with NGPS when explored at 24 and 32 years of age, with 
typical progeria. Skeletal abnormalities and subsequent pain and disability are at the front of the clinical synopsis (Fig. 2) and affect patients' quality of life, making these bones defects a treatment priority. However, NGPS, like progeria, is a post-natal developmental disorder since diagnosis may not be made before the age of 2 years.

After having performed exome sequencing in one family, Puente et al. identified a homozygous missense mutation in BANF1 encoding BAF (Barrier to autointegration factor) as the cause of the NGPS [145]. This was confirmed by sequencing BANF1 in a second family with the same syndrome that retrieved identical mutations and made NGPS an autosomal recessive progeroid syndrome [180]. BAF is a nuclear protein with direct interactions with soluble lamins into the nucleus indicating that HGPS and NGPS share common cellular defective mechanisms and their exploration might lead to the identification of proofs of concept potentially beneficial to patients affected with these two syndromes.

\subsection{Progeroid syndromes associated to DNA repair defective processes}

These progeroid diseases, involving heritable defects in DNA repair, indicate a central role of genome integrity maintenance [181] in the aging process.

\subsubsection{RECQL helicases defective associated syndromes}

Werner syndrome (WS), an autosomal-recessive disorder is also known as progeria of the adult and, in most cases, is associated to null mutations in WRN encoding RECQL2, a protein belonging to the RECQ helicases family with helicase and exonuclease activities. These proteins are crucial for recombination repair as well as telomere maintenance [182]. WS affected patients are at high risk of cancer [183], the major cause of death and shortened lifespan, as this is the case in Bloom syndrome (BS). BS, an autosomal recessive disorder affecting mainly Ashkenazi Jews [184] is associated to mutations in BLM [185] encoding RECQL3, a key player in double strand break repair [186].

Mutations in BS and WS induce a lack of DNA helicase activity. Truncated RECQL proteins do not translocate into the nucleus due to the absence of the NLS located at their C-terminal end [187]. RECQL3 misfolded proteins, also have an abolished function. A lack of exonuclease activity is often associated to RECQL2 deficiency in WS while a lack of ATPase activity may be observed in case of BLM mutations [188]. In this context, two other syndromes may be reported: Rothmund-Thomsom syndrome (RTS), caused by mutations in RECQL4 [189] leading to skin abnormalities as hallmark, and patients susceptibility to cancers, without cognitive impairment [190]; and trichothiodystrophy (TTD), caused by mutations in $X P D$, encoding one of the two transcription factor IIH (TFIIH) helicases [191]. Different XPD mutations can induce TTD, Xeroderma pigmentosum or Cockayne syndrome. XPD encodes a helicase protein involved in both DNA repair and transcription initiation [192]. As a main clinical difference when compared to the previously reported WS and BS syndromes, TTD affected patients present with neurodegeneration including cerebellar ataxia [193].

\subsubsection{Nucleotide excision repair (NER)/base excision repair (BER) associated syndromes}

Cockayne syndrome (CS) is mainly caused by mutations in CSA or CSB [194] with only few patients carrying mutations in XPD. CS proteins are involved in both transcription coupled nucleotide excision repair (TCR) and base excision repair (BER). Recently, mitochondrial contribution to aging-associated symptoms of CS has been reported since CS proteins play also a roles in transcription of mitochondrial DNA [195]. CS patients harbor several symptoms in common with TTD such as neurodegeneration, growth retardation, retinal degeneration and are mentally retarded [196]. Surprisingly, patients have no predisposition to cancer as this is the case in XP, due to a defect in one of seven proteins (XPA to XPG) required for nucleotide excision repair [197]. XP patients show dramatically accelerated aging only in areas of skin exposed to the sun and a skin cancer rate more than a thousand times greater than normal [198]. Moreover they frequently develop neurodegenerative processes $[199,200]$. Genotype-phenotype relationships exist within these three clinically defined but overlapping entities of the NER/BER defective pathways [201]. Finally, nuclear matrix proteins and DNA repair mechanisms exhibit clear relationships, as demonstrated by studying lamin-associated progeroid syndromes [111,202]. As an example, progerin accumulation is induced in cultured fibroblats by UVA-induced oxidative damage resulting in subsequent alternative splicing of the LMNA transcript [203].

\subsubsection{Ataxia telangiectasia (AT)}

AT is caused by a loss-of-function mutation in the ATM (ataxia telangiectasia mutated) gene. ATM is involved in cell cycle progression, checkpoint response to DNA damage, and telomere maintenance [204]. Patients have progressive neurodegeneration leading to cerebellar ataxia at early age, and telangiectatic lesions of early onset [205]. AT patients have a high risk of cancer and are sensitive to UV radiations [206].

\section{Dissecting the pathways leading to aging in progeria and progeroid syndromes}

In a recent very elegant review, Lopez-Otin et al. enumerated nine hallmarks of aging and emphasized that one of the major challenge is to dissect the interrelationships between them [207]: genomic instability, telomere attrition, epigenetic alterations, loss of proteostasis, deregulated nutrient sensing, mitochondrial dysfunction, cellular senescence, stem cell exhaustion and altered intercellular communication. Progeria and other genetic syndromes characterized by an accelerated aging give the opportunity to dissect some of these hallmarks at the cellular level. Farnesylated progerin/prelamin A and mutated A- and B-type lamins or partners within nucleus lead to several structural as well as functional genomic consequences [208,209] (Fig. 4).

\subsection{Abnormal interactions between mutated lamins and protein partners}

Lamin mutations induce abnormal interactions within proteins of NM, lamina, NE leading to nucleus shape defects and to sequestration of components of the genome functional machinery. The deletion of 50 residues at the lamin A C-terminal increases the stability of progerin Ig fold and tail [210], that could explain the disorganization of A- and B-type lamins into lamina of HGPS cells [211]. Nuclear shape and size changes increase in parallel with the amount of farnesylated progerin, giving a crumpled appearance to HGPS nuclei [212], as well as to nuclei, lacking LMNA mutation but expressing progerin, of cells from normal aged subjects [152]. The NE shape alterations, protrusions and invaginations, allow the increase in the NE surface area whereas the nuclear volume remains unchanged [213]. Transcription factors regulating gene expression and numerous other proteins are sequestered into lamina and/or mislocalized in laminopathic cells, a phenomenon impairing several aspects of nuclear genome activity [21,33,214,215].

\subsection{NPC dislocation and impaired nucleocytoplasmic exchanges}

Lamin mutations dislocate NPC resulting, during interphase, in defects in nucleo-cytoplasmic transports of proteins and RNAs, that are essential for all aspects of nuclear genome metabolism. Most of lamin A partners are lamina, NE and NPC proteins, whereas some of 


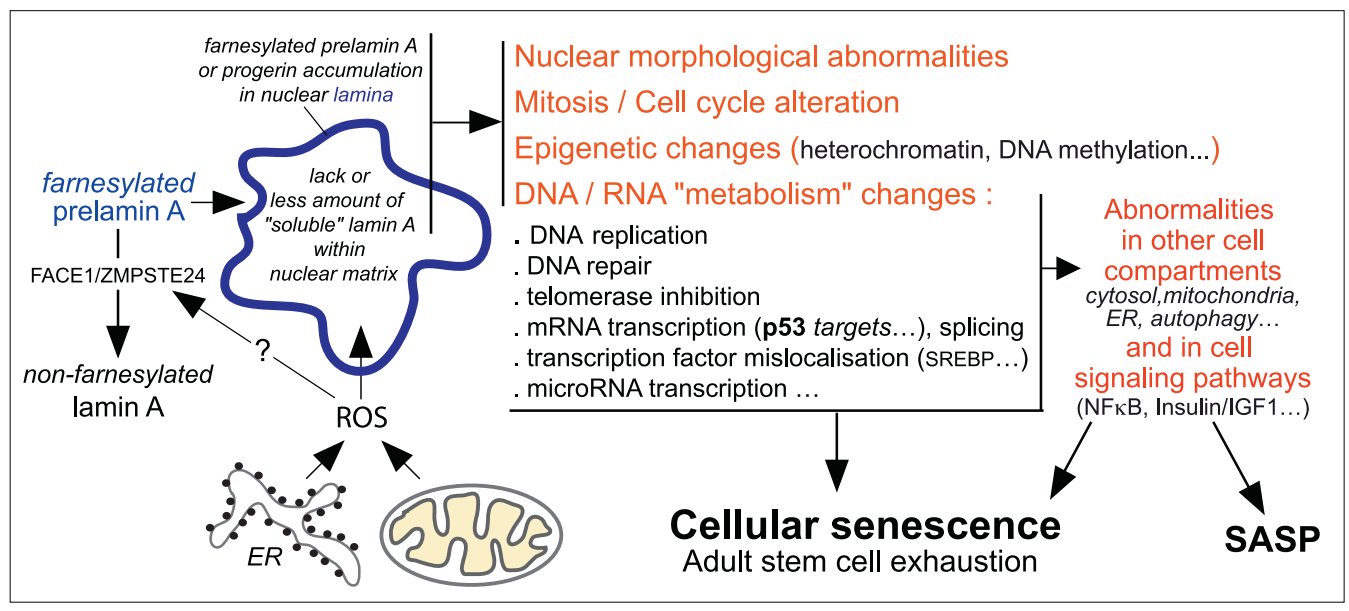

Fig. 4. Cell senescence in laminopathies results from several and combined factors.

them are nucleoplasmic proteins [216]. Both A- and B-type lamins interact with components of NPC [71]. Nuclear protein import is reduced in cells expressing lamin A mutants [217]. The nucleocytoplasmic gradient of monomeric $G$ protein Ran controls the bidirectional transport of proteins and RNAs between the nucleoplasm and cytosol. In HGPS cells, the disruption of this gradient impairs the nuclear import of both the small (19 kDa) SUMO ligase Ubc9, controlling indirectly Ran GTPase activity [218], and of larger proteins such as Tpr (267 kDa), component of the NPC nucleoplasmic basket [219]. ATM and ATR are large proteins whose nuclear import defect and mislocalization impairs DNA repair in HGPS cells [220]. Tpr controls the nuclear level of the SUMO-protease SENP2 and plays a role in the exportin 1-dependant nuclear export of NESbearing proteins [219], of unspliced [221] and polyA+ mRNAs [222]. NPC components also interact with chromatin and control gene expression during interphase [223,224]. Tpr is required for establishing NPC-associated zones of heterochromatin exclusion [225]. In fibroblast cultures from patients with LMNA mutations, live cell imaging evidences intermittent, non-lethal NE disruptions. They allow the nuclear entry of proteins and the nuclear exit to the cytosol of nuclear proteins [226]. This increased NE permeability could be related to the redistribution of phenylalanine-glycine (FG) repeat-containing nucleoporins to the cytosol observed in human muscle cells bearing LMNA mutations [227]. Similar NE events have already observed during HIV [228] and adenoviral infection [229].

\subsection{LMNA mutations induce mechanical defects in non-dividing cells}

A mechanical and functional continuum connect the nucleoplasm content, the nuclear genome and NM, to the extracellular matrix (the basal lamina), through the NE and nuclear lamina, the LINC complexes, each of the three cytoskeletal networks, the plasma membrane and its receptors or cell junctions [230]. Changes in NE, in lamina and in NM composition can result in nuclear shape alterations, that are observed during normal development and differentiation [231], during cell aging and genetic diseases [232], as well as during "acquired" pathologies, such as cancer [233,234], nuclear entry or exit of viruses [235]. NE protein [236] and A-type lamin mutations [212] often evidence dramatic changes in nuclear shape, size and mechanical properties [237], impairing nuclear stiffness [238] and nucleocytoskeletal coupling as often observed in laminopathies [239]. In HGPS cells, the INM protein SUN1, member of LINC complexes, is overexpressed and its reduction corrects nuclear defects and cell senescence, thus evidencing the implication of the nucleocytoskeletal coupling in this disease [240]. A-type lamins defects finally impact bidirectional mechanotransduction and signaling pathways [241] controlling cell interactions with extracellular matrix [242] and chromatin organization [243]. As an example, three parameters, the extracellular matrix stiffness, the lamin A amount and phosphorylation status, the lamin $A$ to $B$ ratio, control the genomic program leading to stem cell and tissue differentiation [133].

\subsection{Cell cycle regulation and mitosis defects in laminopathies}

NM and NE proteins play different roles during mitosis and interphase. NuMA [17], the Ran GTPase [244], some nucleoporins [245], associate with mitotic spindle microtubules and/or with kinetochore, together with cytosolic proteins, e.g. clathrin [246]. They control chromosome segregation and migration, involved in the maintenance of genome integrity, chromosomal stability as well as cell cycle progression.

After microtubule-induced tearing of lamina and NE breakdown [247], B-type lamins, still bound to membrane vesicles through their farnesyl anchor, are part of a RanGTP-induced vesicular membraneous network, controlling mitotic spindle assembly and orientation [248] through interactions with microtubules and motor (dynein, kinesin) and non-motor MAPs (Nudel) [249,250]. Lamin B1 amount is reduced in HGPS cells [251] and in cells as they enter in replicative senescence [252]. In cultured human dermal fibroblasts and keratinocytes and in aged human skin tissue, senescence results from a decrease in lamin B1 amount, linked to both a reduction in $L M N B 1$ transcription and to the inhibition by miRNA 22a of lamin B1 mRNA translation [253]. Silencing the expression of lamin B1 slows cell proliferation and is accompanied by a p53-dependent reduction in mitochondrial reactive oxygen species (ROS) production [254].

The expression of progerin $[255,256]$ or of another lamin A/C mutation L52R [257] slows down as well the cell cycle. Besides mechanical defects (see above), LMNA mutations could result in abnormalities in the nucleocytoplasmic exchanges and nuclear fate of cell cycle regulatory proteins, pRb, cyclin, PCNA [128]. Atype lamins in complexes with LAP $2 \alpha$ promote $\mathrm{pRb}$ localization in perinucleolar lamin $\mathrm{A} / \mathrm{C}$ positive foci, protect $\mathrm{pRb}$ from proteasomal degradation, pRb stabilization being associated with cell cycle arrest [257-261]. pRb amount is lower in HGPS cells that exhibit a defective lamin A-pRb signaling network [262]. The loss of pRb is known to compromise centromere function and cohesion, and to cause chromosome segregation errors, leading to the generation of aneuploid cells [263]. 


\subsection{DNA replication, transcription, repair and epigenetic defects in laminopathies}

A- and to a lesser extent B-type lamins provide a structural support to chromatin and to the nuclear machinery involved in genome functions [254,264]. Human and experimental animal laminopathies offer the opportunity to dissect out the pathophysiological mechanisms of diseases and to analyze their consequences upon cell development, differentiation, survival and aging [209].

\subsubsection{From epigenetics...}

Interphase chromosome territory organization, localization of telomeres and of centromeres, differ in HGPS cells and in cells bearing a progeroid lamin A mutation [265,266] and are associated with alterations in chromatin patterns and in active or silencing marks $[28,251,267,268]$. BAF is a soluble lamina protein, whose insufficiency causes a progeroid syndrome $[145,180]$. BAF interacts with several partners, among them A- and B-type lamins, NuMA, and influences active or silencing marks of histones [269,270]. Aberrant DNA methylation profiles, in particular targeting the NFKB signaling pathway, are among the other epigenetic modifications in cells from HGPS and Werner syndrome patients [271].

\subsection{2. ... to DNA repair. .}

Lamin $\mathrm{A} / \mathrm{C}$ mutants, progerin and farnesylated prelamin $\mathrm{A}$ impair DNA repair, leading to genome instability [85,220,272,273] that represents an important aspect of the aging process [274]. HGPS and RD cells exhibit ROS-induced DNA double-strand breaks [275] that cannot be repaired and are reduced by ROS scavenger treatment [276]. Progerin and prelamin A exhibit elevated binding capacity to SUV39H1, a methyltransferase responsible for $\mathrm{H} 3 \mathrm{~K} 9 \mathrm{me} 3$, and protect it from proteasomal degradation, leading to increased levels of SUV39H1 and H3K9me3. The abnormal H3K9me3-mediated heterochromatin remodeling results in defective DNA repair that can be improved by the depletion of SUV39H1 [277]. Although senescent-associated heterochromatin foci (SAHF) are common in human senescent cells, they are not found in all such cells. In HGPS cells, hybridization with probes to $\alpha$-satellite and to satellite II DNA evidences the unfolding of satellite heterochromatin, another epigenetic change called senescence-associated distension of satellites (SADS). This loss of tight packaging of satellite DNA seems to be more obvious in cells expressing low levels of lamin B1 [278]. It has to be noticed that epigenetic abnormalities or defects in DNA repair could result from impaired nucleocytoplasmic exchanges of the involved proteins (see below) but also from their degradation. LMNA knock-down or mutation in lamin $\mathrm{A} / \mathrm{C}$ rod domain activates several E3-ubiquitin ligases, the proteasomal degradation of HP1 proteins and of ATR kinase, that can be reversed by proteasome inhibitors $[54,279,280]$.

\subsection{3. ... to microRNAs. . .}

MicroRNAs are new actors in the aging field [281,282]. Several miRNA are deregulated in Lmnb1 $1^{-1-} \mathrm{MEF}$, some of them controlling cell cycle [283]. The decrease in lamin B1 amount during aging is caused by miR-23a [253]. In Zmpste24-1- progeroid mice as well as during normal aging in mouse, miRNAs of the miR-29 family are upregulated in response to DNA damage and occurs in a p53dependent manner [284]. In human mesenchymal stem cells (MSC), miR-143p inhibits the translation of FACE1/ZMPSTE24 mRNAs. The lack of the protease leads to the presence of farnesylated prelamin A within nuclei, responsible for MSC aging [285]. The expression of prelamin A, but not of lamin C, is down-regulated by miR-9 in brain neurons and glial cells as well as in neurons derived from iPSC generated from HGPS fibroblasts [286,287]. In HGPS cells, the transcription of several miRNAs is modified, some of them targeting lamin A/C mRNAs [288]. In addition, dysregulation of miRNAs has been also observed in skeletal muscle cells from patients with LMNA-related muscular dystrophy [289].

\subsection{4. ...to transcription and splicing. . .}

Lamins and their partners provide a protein scaffold for the organization of transcription factories, interacting with nuclear and nucleolar RNA polymerase machineries and with several transcription factors regulating gene expression, impaired in laminopathies [215]. Within nucleoplasm, mRNA splicing factors and RNA poymerase II are colocalized in specialized foci, called nuclear speckles or interchromatin granules clusters [290] and surrounded by assembly sites for exon junction core complexes [291]. Nuclear speckles are associated with NM proteins [25,292], and regulate/modulate both transcriptional and post-transcriptional events [293]. Nuclear speckles are also involved in the processing and export of transcripts from genes encoding mitochondrialor ER-targeted proteins and characterized by intron-free 5' UTR [294]. An age-associated disruption in the balance of alternatively expressed isoforms for selected genes suggests that modification of mRNA processing may be a feature of human aging [295]. This imbalance is related to the decrease in the expression of about $38 \%$ of splicing factors and of ATM [296], thus linking pre-mRNA processing and DNA damage response [297]. Downregulation of splicing factor SRSF3 induces an alternatively spliced isoform of p53 that promotes cellular senescence [298]. Senescence-associated stress signals result in the cytoplasmic accumulation of several splicing factors such as SRSF1 in endothelial cells [299], their shuttling being controlled by their phosphorylation status and by RanBP2 (Nup358), constituting the cytoplasmic filaments of NPC [300]. Two splicing factors, SRSF1 and 6, exihibit opposite effect on the progerin production by HGPS fibroblasts [301]. The progeriaspecific cryptic splicing site in exon 11, leading to progerin mRNA, is activated during physiological aging, without LMNA mutation $[152,302]$. This splicing machinery defect is reminiscent to another age-related transcription abnormality, where the missreading of GAGAG motifs, within genes involved in Alzheimer disease, lead to the GA dinucleotide deletion in mRNAs and the synthesis of mutated proteins in the absence of mutation within the genes [303]. A similar transcription infidelity is also observed in cancers [304]. In normal human fibroblasts, progressive telomere shortening during cellular senescence induces progerin production through the activation of the cryptic alternative splicing site in $L M N A$ exon 11 , thus evidencing a synergistic relationship between telomere dysfunction and progerin production [305].

\subsection{Telomerase complex defects in laminopathic cells}

Accelerated telomere shortening and replicative senescence is observed in LMNA null cells [202] and in cells (over)expressing mutant and wild-type lamin A [306-308]. This phenomenon can be corrected by telomerase overexpression or p53 inactivation [309]. Telomerase complex defect could be related to epigenetic changes in telomeric heterochromatin [268,310]. In human senescent mesenchymal stem cells or in cells expressing mutant lamin A or B, telomeres (and centromeres) aggregate with nuclear lamina and are colocalized with phosphoH2AX, but not with telomerase catalytic subunit TERT, suggesting that telomere aggregates are sites of DNA damage [311]. The telomere mobility is increased in cells lacking A-type lamins, is reduced in HGPS cells [312]. An oxidative stress including ROS overproduction and a reduced level of antioxidant defenses is encountered in the two types of progeroid syndromes, laminopathies and DNA damage response defects [313-316] (see below Section 3.8). Upon oxidative stress, TERT can shuttle from the nucleus to the mitochondria, where it protects mitochondrial function, decreases mitochondrial ROS levels and prevents nuclear DNA damage, but does not correct telomere shortening [317,318]. 
Reciprocal relationships have been observed between TERT and the Wnt/ $\beta$-catenin signaling pathway involved in cell differentiation (see below Section 3.10) [319,320]. In hematopoietic stem cells, in heart and liver from Tert $^{-1-}$ mice, telomere dysfunction activates p53 which in turn binds and represses two master regulators of mitochondrial metabolism (PGC- $1 \alpha$ and PGC-1 $1 \beta$ ), thereby impairing mitochondrial biogenesis and function, increasing reactive oxygen species production and forging a direct link between telomere and mitochondrial biology [321].

\subsection{Abnormal p53 signaling}

p53 functions is a transcription factor involved in cell-cycle control, DNA repair, apoptosis and cellular stress responses. However, p53 also modulates cell senescence and organismal aging, as p53 stands at the crossroad of several mechanisms: mitochondrial function, ROS generation and scavenging, mTOR signaling and autophagy [322] and telomerase activity. The activation of $\mathrm{p} 53$ (and of $\mathrm{pRb}$ ) signaling pathways is observed in cells bearing mutations in A-type lamins [308,323] or in FACE1/ZMPSTE24, the phenotype of Zmpste24-/- mice being improved by breeding with p53-1- mice [324]. Citrullination of lamin C (and of histone H4), that could be a pro-apoptotic signal, is triggered by DNA damageinduced p53 activation [325]. The activation of p53 reduces lamin B1 level $[252,253]$. A p53 binding site on the LMNA promoter controls the p53-induced increase in lamin A/C. p53 also increases lamin B2 level but lacks a binding site in LMNB2 promoter [326]. Cell cycle, p53 and pRb expression are also controlled by emerin, LAP2 and other less characterized NE transmembrane proteins [327]. The NM protein NuMA also modulates the expression of p53 target genes $[113,114]$. During the replicative senescence of human normal fibroblasts, the downregulation of SRSF3 induces the upregulation an alternatively spliced isoform of p53 that promotes senescence [298]. Besides protein coding genes, p53 also controls the expression of several microRNAs [328]. For example, miR-34a, whose maturation requires the splicing of a $30 \mathrm{~kb}$ intron [329], up- or down-regulates more than two hundred of genes [330,331], among them LMNB1 and LMNB2. Furthermore p53 also regulates several actors of the miRNA processing complex [332]: miR-9, known to inhibit the expression of lamin A within neuron and glial cells, regulates DGCR8, a dsRNA binding protein involved with Drosha in the first cleavage of pre-miR; miR-29 inhibits both the mRNAs of DICER and of FACE1/ZMPSTE24 [284,333]; miR-143 and miR-34 control the expression of exportin 5, responsible for pre-miR nuclear export, that is activated during the ATM-induced the DNA damage response [334].

\subsection{Mitochondria, endoplasmic reticulum, oxidative stress and nuclear-mitochondria signaling}

A- and B-type laminopathies are accompanied by altered levels of ROS and by a higher susceptibility to oxidative stress [315,316]. Mitochondria are the major source of ROS [335], mainly produced by complexes I and III of the respiratory chain [336]. ROS, besides their toxic effects, also elicit various physiological events from differentiation to aging [337]. Mitochondrial DNA only encodes 13 proteins inserted into inner membrane, whereas the other $\sim 1100$ proteins are encoded by nuclear genome, synthetized into cytosol and imported into mitochondria [338]. Normal human aging is associated with a progressive decline in muscle mitochondrial DNA abundance and protein synthesis that plays a major role in regulation of life span [339]. The specific loss of mitochondrial, but not nuclear, encoded respiratory chain subunits results from a non-classical nuclear to mitochondrial communication pathway triggered by a decrease in nuclear NAD+ content. The phenomenon can be reversed by raising NAD+ levels [340]. Transcription of genes encoding mitochondrial proteins is impaired during laminopathies leading to an imbalance between mitochondrial and nuclear proteins especially those constituting complexes I, III and IV of the respiratory chain and the ATPsynthase [341-343]. This imbalance triggers the mitochondrial unfolded protein response (UPRmt) [344], whereby mitochondria send a signal to the nucleus to induce the production of stress-related proteins, which restore the mitochondrial balance. The increased UPRmt is correlated with longer lifespan in mice and in Caenorhabditis elegans [345]. One of the genes activated by the UPRmt is CHOP, also involved in the ER unfolding protein response [346], and activated in cells bearing R482W mutant lamin A [347]. Mitochondria and ER domains interact in MAM (Mitochondria-associated membranes), that represent highly specialized platforms involved in several functions [348] among them NFKB activation and autophagy [349]. The imbalance between nuclear and mitochondrial proteins could also result from the overexpression of miRNAs in brain and liver of aged mice, that target selectively mRNAs encoding subunits of complexes I, IV and of ATPsynthase [350]. Mitochondria elicit dynamic relationships with cytosolic P bodies involved in mRNA decay through miRNAs. The inactivation of mitochondria by CCCP leads to a strong decrease of miRNA efficiency [351].

\subsection{NFKB, "inflammaging" and senescence-associated secretory phenotype (SASP)}

Known as a family of ubiquitously expressed transcription factors activated in response to cell stress and mediating innate and adaptive immunity, NFKB is involved in the induction of cell senescence [352]. NFKB signaling pathway is activated in three different mouse progeroid models bearing defect in DNA repair [353] or in prelamin A processing [354]. Mice aging is slowed down and lifespan is rescued by pharmacological inhibitors of NFKB signaling pathway or by crossing the progeroid mice with mice defective in one (RelA/p65) of the NFKB protein complex, thus leading to the inactivation of the pathway. Senescent cells secrete a growing collection of factors that alter their microenvironment and the neighboring cells in a paracrine way, a phenomenon called the senescence-associated secretory phenotype (SASP), whose NFкB is a major regulator [355-357]. Vascular smooth muscle cells (VSMC) from aged subjects or aging in vitro express farnesylated prelamin A, due to a decreased amount in FACE1/ZMPSTE24 mRNA and protein [358]. Prelamin A expression by these cells induce a SASP and promote VSMC calcification [359]. Besides signaling proteins and other aging-inducing factors, several miRNA appear to be secreted by aged cells and to participate to SASP [360]. miRNAs are secreted in exosomes or microparticles, are exchanged by cells and modulate gene expression in target cells [361-363].

\subsection{Adult stem cell exhaustion related to defects in signaling pathways}

Naive adult mesenchymal stem cells from HGPS patients express low levels of progerin in vivo but accumulate nuclear progerin with increasing passages in vitro [364]. The presence of farnesylated prelamin $A$ or of progerin in nuclei of epidermal [365] or mesenchymal [366] adult stem cells lead to their progressive exhaustion, another pro-aging phenomenon, linked to defects in Wnt or Notch signaling pathways respectively. In another progeroid mouse model $\left(\operatorname{Lmna}^{\Delta 9 / \Delta 9}\right)$, the deletion of exon 9 causes the proliferative arrest and death of postnatal, but not embryonic, fibroblasts. The defects are associated with inhibition of the $\mathrm{Wnt} / \beta$-catenin signaling pathway, resulting in the inability of cells to synthetize a functional extracellular matrix (ECM) [241]. The synthesis of $\beta$-catenin is controlled by two splicing factors, SRSF1 
and 9, exhibiting an aging-related decrease [296] that could explain the Wnt/ $\beta$-catenin signaling defect. The same two SRSF are overexpressed in cancer cells and promote Wnt-signaling tumorigenesis through the production of $\beta$-catenin mRNA [367].

Two other studies evidence the anti-aging role of diffusible factors secreted by wild-type adult stem cells. Adult skeletal muscle stem cells from two progeroid XP $\left(\operatorname{Ercc1}^{-/-}\right)$or RD (Zmpste24-/-) mouse models, show impaired muscle regeneration, reduced proliferation and myogenic differentiation in vitro. Progeroid symptoms are corrected in $\mathrm{FrcC}^{-1-}$ mice by the intraperitoneal transplantation of adult skeletal muscle stem cells from wild type mice [368]. Proliferation and myogenic differentiation in vitro of Zmpste24-/- adult skeletal muscle stem cells are rescued by yet unknown factors secreted in the conditioned medium by adult skeletal muscle stem cells from wild-type mice [369].

\subsection{Autophagy is altered in laminopathies}

Eukaryotic cells have two major systems for the regulated degradation of proteins. The membrane-dependent autophagiclysosomal pathway interests both membrane organelles and cytosolic proteins. The ubiquitin-proteasome system (UPS) is restricted to nuclear and cytosolic proteins [370], some of them being retrotranslocated into the cytosol from the ER, through the ERAD mechanism [371]. Proteasome function is impaired during aging, suggesting that this decrease in proteasomal activity might be involved in the aging process and in the occurrence of age-associated diseases [372,373]. Mammalian cells exhibit three types of autophagy mechanisms: chaperone-mediated autophagy, microautophagy and macroautophagy [374]. Several observations changed recently the view that UPS and macroautophagy are independent degradative pathways. For example, ubiquitylation target substrates for degradation via both pathways; perturbations in the flux through either pathway affect the activity of the other system [375]; ubiquitylation of mitochondrial outer membrane proteins triggers mitochondrial autophagy (mitophagy) [376,377].

Furthermore, several cross-talk have been reported between aging, UPS and autophagy degradative pathways [378] and their triggers, activators or regulators, DNA damage [379,380], mitochondria dysfunction and oxidative stress [375,381], ER stress [382,383], p62/SQSTM1 [384,385], p53, NF-кB and partners [356,386-389]. Macroautophagy regulation becomes recently more complex through the involvement of a transcriptional network, microRNAs and epigenetic histone marks [390]. Chaperonemediated autophagy (CMA) activity declines with age, due to a decrease in the stability and in the net content of LAMP-2A in the lysosomal membrane. Genetic manipulations aimed at preventing the decrease of LAMP-2A with age, through the expression an exogenous Lamp-2A in mouse liver, restore CMA activity and extend mouse life-span [391]. Macroautophagy also declines with age, its inhibition leading to premature aging, while its activation delays aging and extend longevity, through cell and organismal effects (innate immunity, inflammatory responses, neuroendocrine regulation) [392]. These observations lead to pharmacological approaches to fight against aging in laminopathies (see Section 4.3 below). However, a paradoxal up-regulation of basal macroautophagy is observed in progeroid Zmpste24-/- mice, that is linked to mTOR inhibition, AMPK activation and severe metabolic alterations in glucose and lipid metabolism [393].

\section{Therapeutic approaches in progeria and lamin A-related progeria-like syndromes}

Three main strategies have been designed to correct the defects in progeroid syndromes linked to prelamin A processing
(Fig. 5): to decrease the toxicity of farnesylated prelamin; to block the cryptic splicing site leading to mature progerin mRNA production; to degrade progerin or farnesylated prelamin A within cells. Only the first strategy led to therapeutic trials in human patients up to date. In addition, targeting the insulin-IGF1 signaling pathway has also been investigated in a progeroid mouse model.

\subsection{Decreasing progerin/prelamin A toxicity by reducing their isoprenylation}

Three human genetic diseases leading to accelerated aging, mandibuloacral dysplasia, progeria and restrictive dermopathy, elicit the same pathophysiological mechanism: mutation in either LMNA or in the ZMPSTE24 results in the persistence within cells of farnesylated proteins, progerin or prelamin A. Among several stud-

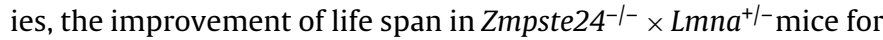
example evidences that the cell toxicity is linked to the farnesyl moeity bound to progerin or to prelamin A [394]. Two strategies have been designed targeting the isoprenoid biosynthesis pathway (Fig. 5D).

Farnesyl-transferase inhibitors (FTI), designed to block the activation of Ras in several cancers [395], were used to block or minimize progerin/prelamin A farnesylation. FTI gave better results in cultured cells from human patients than in mouse models of progeroid syndromes or expressing various isoforms of progerin or of (pre)lamin A, either prenylated or not. Indeed only a small percentage of progerin/prelamin A seems to be unprenylated in FTI-treated animals [396,397]. FTI improve some parameters (e.g. nuclear shape) in cultured cells but not other parameters such as the DNA damage response [220].

From 2007 to 2009, an FTI (lonafarnib) was given to 25 patients enrolled in the first therapeutic trial for progeria that took place in Boston Children's Hospital (Clinicaltrials.gov identifier NCT00916747). The published results [398] do not evidenced a clear improvement for the main endpoints. Body weight gain under FTI, was presented as increased by $50 \%$ in 6 children, as compared to the expected weight gain when untreated. However, a previous natural history study, in a cohort of untreated progeria children, indicated that the mean weight gain was very similar [156]. In all other patients, the rates of weight gain were either stable or decreased [399]. HGPS patients under FTI treatment developed many side effects, most of them known as being related to the molecule. This was not surprising since it was demonstrated that an alternative prenylation pathway, geranylgeranylation, toxic as well, was activated in the presence of FTI The published results [414] did not indicate a clear improvement for the main endpoints. Body weight gain under FTI, was presented as increased by $50 \%$ in 6 children, as compared to the expected weight gain when untreated. However, a previous natural history study, in a cohort of untreated progeria children, indicated that the mean weight gain was very similar [156]. In all other patients, the rates of weight gain were either stable or decreased [415]. HGPS patients under FTI treatment developed many side effects, most of them known as being related to the molecule. This was not surprising since it was demonstrated that an alternative prenylation pathway, geranyl-geranylation, toxic as well, was activated in the presence of FTI [85]. However, potentially interesting results on the cardiovascular system protection were reported [399].

The benefit of FTI for progeria is controversial since donutshaped nuclei appear in cultured cells and in tissues from wild type mice or from human progerin expressing model after FTI treatment, a phenomenon linked to an increase of the proteasomal degradation of pericentrin, a centrosomal protein [400]. Stop mutations in pericentrin lead to dwarfism [401] and to 


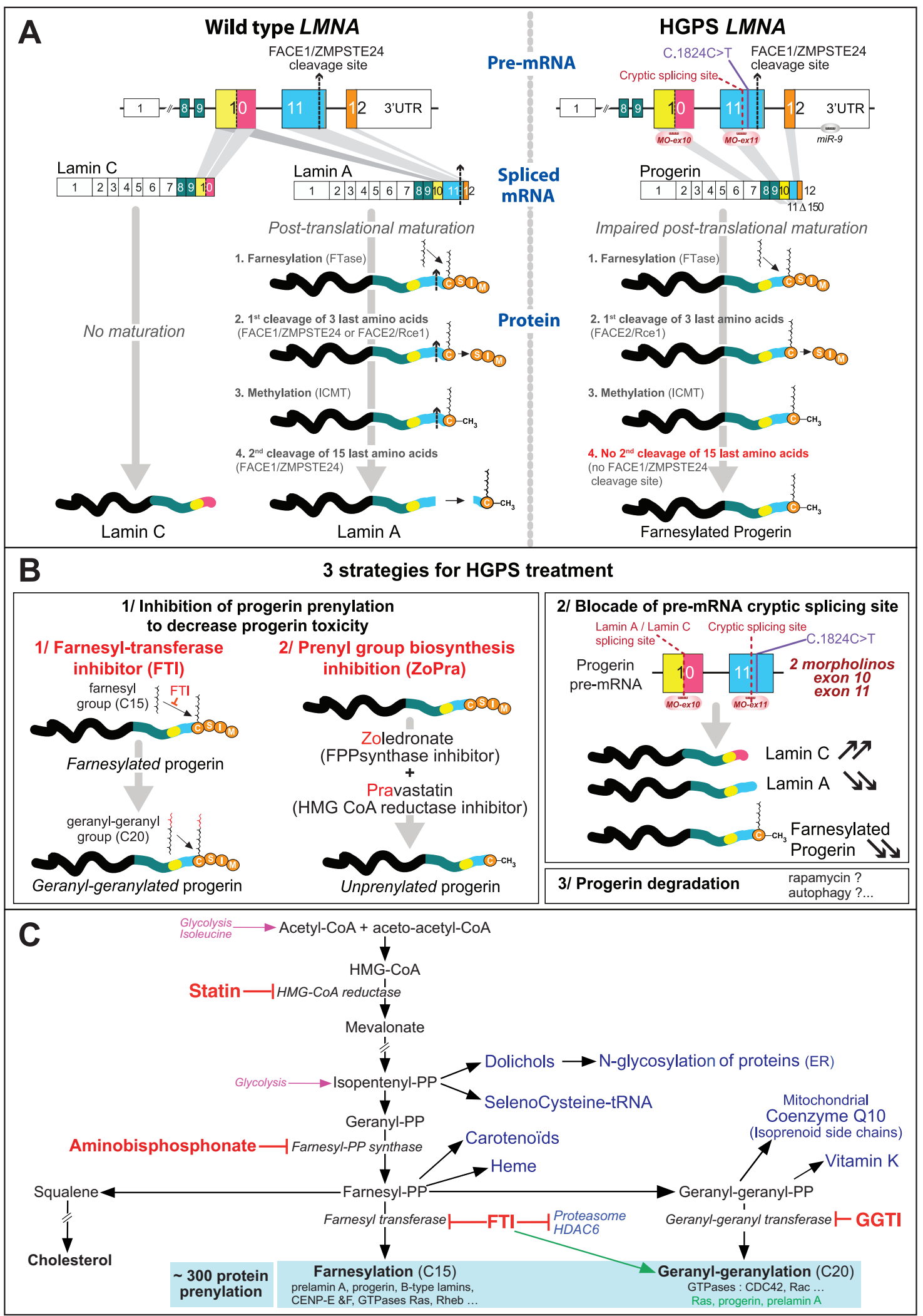

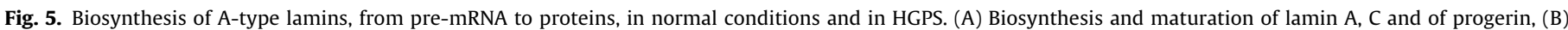

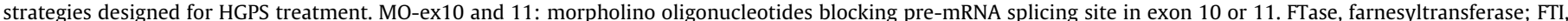

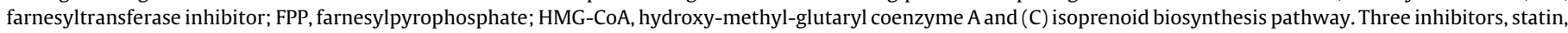
aminobisphosphonate, farnesyltransferase inhibitor are approved for human therapeutic use. GGTI, inhibitor of type I geranyl-geranyl-transferase. 
abnormalities in ATR-dependant DNA damage response [402]. FTI are known inhibitors of the histone deacetylase HDAC6 [403,404], whose main cytosolic targets are $\alpha$-tubulin [405], tau [406] and several other MAP [407]. Therefore, FTI-induced nuclear shape abormalities could result from defects in both mitotic spindle microtubules and in centrosome organization and functions [408].

Another pharmacological strategy targeting progerin/prelamin A isoprenylation was designed and tested in HGPS cultured cells and in $\mathrm{Zmpste} 24^{-/-}$mice model, that combines the inhibitors of two enzymes of the isoprenoid biosynthesis pathway: an aminobisphosphonate (zoledronate, Zo) for farnesyl-pyrophosphate synthase and a statin (pravastatin, Pra) for HMG-CoA reductase [85]. This synergistic ZoPra combination offers the advantage to block both farnesylation and geranyl-geranylation of progerin/prelamin A, avoiding the alternative isoprenylation by geranyl-geranyl transferase I induced by FTI, already reported for Ras [409,410]. The alternative geranyl-geranylation of prelamin $\mathrm{A}$ and of progerin, as well as its similar toxic effect as compared to prelamin A farnesylation, was demonstrated in mass spectrometry experiments, after FTI but not after ZoPra treatment [85]. It is also of note that Zoledronate activates macroautophagy in human PC3 prostate cancer cells [411].

Twelve patients received the ZoPra combination from 2008 to 2013 in the European clinical trial for progeria that was organized in Marseille's La Timone Children's Hospital (Clinicaltrials.gov identifier NCT00731016) [412]. Interestingly, it was demonstrated that a similar combination associating another statin (lovastatin) and another farnesylpyrophosphate synthase inhibitor (N6-isopentenyladenosine) blocks progerin and prelamin A isoprenylation in cultured cells [413].

An additional therapeutic trial is currently in progress in Boston associating the FTI lonafarnib, a statin (pravastatin) and an aminobisphosphonate (zoledronate) (Clinicaltrials.gov identifier NCT00916747). One has to notice that this triple-drug regimen induces more donut-shaped nuclei than the treatment by FTI alone [400]. Furthermore, no in vivo pre-clinical studies were performed to evaluate the efficacy and eventual toxicity of this triple drug combination, and their additive toxicities remain questionable.

\subsection{Blocking progerin mRNA cryptic splicing site in vitro and in vivo}

An elegant experiment demonstrated that a short (25-mer) antisense morpholino oligonucleotide can sterically blocks the cryptic splicing site of progerin pre-mRNA in exon 11, induces the concentration-dependant decrease in progerin mRNA and protein and reverses the phenotype of cultured cells from progeria patients [251]. A similar strategy was tested on Zmpste24 $4^{-/-}$mice and on a progeria mouse model (Lmna ${ }^{G 609 G / G 609 G}$ ) designed by our team in close collaboration with Carlos Lopez-Otin team in Oviedo (Spain). Phosphorodiamidate morpholinos, modified by covalent binding of octaguanidin dendrimere, in order to increase the uptake of oligos by tissues [414], were administered by IV injection and showed a clear correction of progeria phenotype as well as a significant lifespan extension extended life span in this progeria mouse model. Two oligonucleotides were associated, the first one blocking the exon 11 cryptic site and the other one targeting the exon 10 splicing site, directing the production of mRNAs encoding lamin $C$ or lamin A, in order to favor splicing toward lamin C mRNA [415]. Together with the increasing evidence that the use of oligonucleotides for splicing redirection has growing therapeutic applications in animal models and in human diseases [416], this prompted our team, in close collaboration with Carlos López-Otín, to set up a clinical trial under design.

\subsection{Progerin degradation through macroautophagy in cultured} cells

The mammalian targets of rapamycin (mTOR) complexes are two key modulators of cell growth, aging and age-related diseases, integrating nutrient and hormonal signals, and are inhibited by rapamycin $[417,418]$. This macrolide antibiotic is approved by the U.S. Food and Drug Administration for several clinical applications, including immunosuppression [419,420]. Among a broad range of biological pathways, rapamycin extends life span from yeast to mammals [421], activates macroautophagy [422,423], a mechanism that could benefit to aging and the treatment of degenerative diseases [386].

In cultured HGPS fibroblasts, rapamycin reduces progeria phenotype cell symptoms and increases the clearance of progerin by inducing macroautophagy [424]. Rapamycin also improves the health status of skeletal and cardiac in $\mathrm{Lmna}^{-1-}$ mice [425], whereas another mTOR inhibitor corrects the cardiomyopathy exhibited by Lmna $^{H 222 P / H 222 P}$ mice through the same mechanism [426]. Besides reducing progerin level, rapamycin restores BAF and LAP $2 \alpha$ normal levels and distribution in HGPS cells [427]. In fibroblasts from centenarian subjects, FACE1/ZMPSTE24 downregulation results in the accumulation of farnesylated prelamin A, inducing the nuclear import of 53BP1, one of the DNA damage response actors. In these cells, rapamycin activates macroautophagy that probably degrades selectively farnesylated and carboxymethylated prelamin A but not full-length prelamin A [428]. In Werner syndrome cells, rapamycin restores also some of the consequences of DNA damage [429,430]. These data prompted to plan to increase the autophagic clearance of progerin through the use of mTOR complexes inhibitors, in the treatment of human progeria patients. The "4-drug trial", associating an FDA-approved mTOR inhibitor, an FTI, zoledronate and pravastatin has been announced [431].

Despite these encouraging data from in vitro experiments, caution should remain a topical issue when thinking to treatment of human patient with rapamycin. This drug shortens the life span of progeria $L m n a^{\mathrm{G} 609 \mathrm{G}}$ mice, and reduces their body weight (Navarro et al., publication in preparation). FTI is also known to be an inhibitor of mTOR complexes in melanoma cells [432]. The first upstream activator of mTOR, the small GTPase Rheb, is the farnesylated protein [433]. The inhibition of Rheb farnesylation by FTI blocks mTOR activation [434] and its downstream activities among them autophagy [435]. Besides, HDAC6, another regulator of macroautophagy [436,437], is inhibited by FTI. Therefore, the macroautophagy activation by rapamycin could be strengthened by protein prenylation inhibitors.

\subsection{Correction of endocrine, metabolic and inflammatory signaling pathways}

The insulin and IGF1 signaling pathway, its several targets and their regulators, among them the transcription factors of FOXO family, the sirtuins [438], the Klotho hormone [439], the mTOR complexes (see above), represents the most conserved network controlling aging from nematodes to humans [440-442]. The insulin and IGF1 signaling pathway exhibits several crossrelationships with other aging-controlling pathways, such as proteostatis [443], oxidative stress and mitochondria [444,445], innate immunity and inflammatory responses through NFKB network [446], recently shown to control hypothalamic neuroendocrine activity [447]. The inhibition of NFKB signaling pathway slows down aging and recues lifespan in different progeroid mice models $[353,354]$. The administration of recombinant IGF1 to Zmpste24-/- mice, that present extremely high levels of growth hormone $(\mathrm{GH})$ and a drastic reduction in plasma IGF1, restores the normal balance between IGF-1 and GH, delays the onset of many 
progeroid features, and extends the lifespan of these progeroid animals [448]. Resveratrol, a natural activator of Sirtuin 1 [449], extends the lifespan of the same mice model [450]. Two INM transmembrane proteins could be involved in the modulation of the mTOR-IGF2-AKT signaling pathway, one master regulator of skeletal myogenesis [451]. NET39 blocks IGF2 transcription by inhibiting mTOR activity at the NE [452], whereas NET37, through its glycosidase activity, contributes to the maturation of pre-IGF2 in the secretory pathway and therefore to the activation of the pathway promoting myogenesis [453].

\section{Recent and promising issues: iPSC, mouse models}

\subsection{Induced pluripotent stem cells (iPSC)}

Derived from adult cell types, iPSC have enabled the creation of patient-specific stem cells, giving the opportunity to identify aberrant disease-associated pathways allowing disease modeling [454-456]. iPSC are used for in vitro development and testing of new therapeutic agents and regimens [457], for high-throughput drug screening $[458,459]$ and imaging in industrial platforms [460]. iPSC have been derived from HGPS [461] and Werner syndrome cells [462]. Adenoviral vectors can be used to provide large genomic regions that correct $L M N A$ mutations in HGPS iPSC and their derived mesenchymal stem cells [463]. Lamin A level influences the induction of iPSC, the higher lamin A level, the lower reprogramming efficiency of somatic cells into iPSC. Reduced levels of lamin A are associated with increased expression of pluripotent genes Oct4 and Nanog, and of telomerase genes Tert and Terc [464]. As progeroid syndromes affected mainly cells from mesenchymal lineage, HGPS iPSC have been differentiated into several derivates from mesenchymal stem cells [465], cardiomyocytes [466] and adipocytes, whose differentiation is impaired through the inhibition by progerin of two transcription factors, PPAR 22 and C/EBP $\alpha$ active at late stage [467]. HGPS iPSC were also differentiated into neural cells [465], where miR-9 negatively controls lamin A and progerin expression [287]. An original strategy offers an unique opportunity to model late-onset human pathologies, such as neurodegenerative diseases. The expression of progerin has been induced in iPSC-derived fibroblasts sampled from Parkinson disease patients, after transfection with modified progerin RNAs produced by in vitro transcription. This strategy allows to analyze the progerin-related aging by dopaminergic neural cells [468].

\subsection{Mouse models}

Besides FACE1/ZMPSTE24, two other ER enzymes are involved in A- and B-type prelamin post-translational processing. FACE2/Rce $1^{-1-}$ mice died during late gestation or soon after birth [469], whereas ICMT-deficient mice exhibit a more severe phenotype [470].

Breding Zmpste24-/- mice with $I \mathrm{~cm} \mathrm{t}^{\mathrm{hm} / \mathrm{hm}}$ mice, expressing hypomorphic alleles of ICMT, corrects the progeroid phenotype of Zmpste24-1- mice. The decrease in the amount of methylated prelamin A is associated with increased AKT-mTOR signaling pathway, but does not improve the nuclear shape. The last result adds to the evidence that nuclear shape correction alone has only little relevance in exploring progeria, and that its correction should not be an endpoint during clinical trials. However, decreasing ICMT activity might be a new way for treating prelamin A-associated progeroid disorders [471].

Finally, an elegant mice model highlights the hypothesis that supplementation by systemic factors or cell-based therapies (see Section 3.9) are of great promise for the treatment of progeroid syndromes, while opening new fields in aging-related cancer or degenerative diseases.

By the use of crossing strategies coupled to recombination, Zmpste24 mosaic female mice were obtained. While they are null for the autosomal Zmpste24 locus, they contain an extra copy of Zmpste24 gene introduced in their $\mathrm{X}$ chromosome. Because of random $\mathrm{X}$ inactivation, contains, these mice contain in a similar proportion, two cells types: Zmpste24-deficient ones, accumulating farnesylated prelamin A; and Zmpste24-expressing cells in which prelamin A maturation is normal.

Mosaic mice develop normally and do not express progeria markers, thus evidencing that the development of progeroid phenotype is under the control of cell-extrinsic mechanisms. Furthermore, as farnesylated prelamin A accumulation prevents the initiation and the invasion of tumors triggered by known chemical carcinogens, this mice model strongly suggests that the prelamin A processing FACE1/ZMPSTE24 metalloprotease could be a new target for cancer therapy [472].

\section{Conclusion}

None of the known progeroid syndromes recapitulates global aging. All of them are characterized by segmental premature and accelerated aging, many of those involving defective DNA repair mechanisms and genomic integrity are associated to high predisposition to malignancies, while others such as HGPS, MAD, NGPS and CS, do not correlate with an increased risk of cancer.

Premature and accelerated aging diseases constitute a heterogeneous group of rare diseases, among which several entities have been nosologically defined. Most of them are genetically determined as being genetically inherited with at least one major gene being in cause. However, while progeria and other related defective prelamin A associated syndromes, as well as numerous defective DNA repair associated syndromes have been deeply characterized at the clinical and pathophysiological levels, other aging syndromes remain to be elucidated. Exploring and characterizing these disorders is of major interest for at least three main reasons. First in terms of human rights, considering that any individual must equally benefit from research programs in health, and have an equal access to care. Even patients affected with rare or exceedingly rare diseases, like progeria with probably no more than 200 living children worldwide, should be able to get scientists' attention in order to better characterize their disease at the clinical, genetic, and cellular levels and develop therapeutic approaches. Second, many examples have demonstrated that rare diseases may be essential for understanding more common diseases or physiological mechanisms. In this instance, progeria and related disorders represent a perfect paradigm. Mis-processed progerin, first identified in progeria, was demonstrated to be physiologically produced and progressively accumulated through the entire life, and further studies have shown its involvement as one of the mechanisms of natural aging. Third, translational research aiming at filling the gap between the identification of proofs of concept molecules and patient's inclusion in early phases of clinical trials may be considerably accelerated, taking advantage of specific access conditions for the use of therapeutic molecules. Repurposed and innovative molecules identified through research programs in rare diseases may benefit from orphan drug designations and accelerated procedures designed by regulation agencies. In that, it is remarkable to note that in a matter of five years after the 1 st identification of the main mutation affecting progeria, two independent Phase II therapeutic trials have been designed and started, one in the US and the other in France, this latter using a combination of molecules having obtained the orphan drug designation and being developed toward obtaining EMA and FDA approval. 
Each premature aging disease only partially recapitulates physiological aging. However, each of these clinically and pathophysiologically elucidated distinct entities is associated to a specific mechanism involved in normal aging. Many studies have demonstrated aging pathways' interactions. This is the case for DNA repair machinery whose defects directly induce premature aging diseases, but also play a key role in defective prelamin A associated syndromes, themselves involving p53 and its targets' activation. Development of molecules for rare aging diseases will help treat disorders usually associated to physiological aging as well as it could help patients affected with deficient p53 associated cancers.

In all, different research approaches have been used to study aging, but studying monogenic segmental progeroid syndromes is certainly one of the most promising. This will not only provide major insights and accelerate our understanding of senescence and aging, but should, in the end, change patients' life and, hopefully, be beneficial for children affected with these dramatic and devastating diseases that continue to kill at early age.

\section{Acknowledgments}

We thank all patients and families for their continuous cooperation and support to our studies. We warmly acknowledge all the members of the lab and in particular the team 2 "Nuclear matrix and diseases" for helpful comments and discussions. Andrée RobagliaSchlupp \& Karine Bertaux as being in charge of the Center for Biological Resources in the department of medical genetics, have a major contribution to the studies performed in our laboratory.

Overall, the authors are extremely grateful to Prs. Carlos LópezOtín and Raoul Hennekam for their wonderful and long term support and collaboration, and for providing us with the clinical pictures used in this article. We are also thankful for Dr Hedi Claahsen's collaboration and for providing a clinical picture.

Our studies on Progeria and related disorders are supported by Aix Marseille University, Institut National de la Santé et de le Recherche Médicale, Assistance Publique des Hôpitaux de Marseille and by grants from the Association Française contre les Myopathies (AFM-Téléthon) to NL, Agence Nationale de la Recherche to NL, Agence Nationale de la Recherche contre le Sida to PC, Sidaction to PC, PHRC program from the French Ministry of Health to NL, Fondation maladies rares to NL. CN, KH and SP are postdoctoral fellows supported by AFM-Telethon ( $\mathrm{CN}$ and $\mathrm{KH}$ ) and PrenylB company (SP).

\section{References}

[1] Grossman E, Medalia O, Zwerger M. Functional architecture of the nuclear pore complex. Annu Rev Biophys 2012;41:557-84.

[2] Blobel G. Three-dimensional organization of chromatids by nuclear envelopeassociated structures. Cold Spring Harb Symp Quant Biol 2010;75:545-54.

[3] Hetzer MW. The nuclear envelope. Cold Spring Harb Perspect Biol 2010;2:a000539.

[4] Vlcek S, Foisner R. Lamins and lamin-associated proteins in aging and disease. Curr Opin Cell Biol 2007;19:298-304.

[5] Schirmer EC, Florens L, Guan T, Yates 3rd JR, Gerace L. Nuclear membrane proteins with potential disease links found by subtractive proteomics. Science 2003;301:1380-2.

[6] Chen IH, Huber M, Guan T, Bubeck A, Gerace L. Nuclear envelope transmembrane proteins (NETs) that are up-regulated during myogenesis. BMC Cell Biol 2006;7:38.

[7] Korfali N, Wilkie GS, Swanson SK, Srsen V, Batrakou DG, Fairley EA, et al. The leukocyte nuclear envelope proteome varies with cell activation and contains novel transmembrane proteins that affect genome architecture. Mol Cell Proteomics 2010;9:2571-85.

[8] Gomez-Cavazos JS, Hetzer MW. Outfits for different occasions: tissue-specific roles of nuclear envelope proteins. Curr Opin Cell Biol 2012;24:775-83.

[9] Korfali N, Wilkie GS, Swanson SK, Srsen V, de Las Heras J, Batrakou DG, et al. The nuclear envelope proteome differs notably between tissues. Nucleus 2012;3:552-64.

[10] de Las Heras JI, Meinke P, Batrakou DG, Srsen V, Zuleger N, Kerr AR, et al. Tissue specificity in the nuclear envelope supports its functional complexity. Nucleus 2013;4:1-18
[11] Linnemann AK, Krawetz SA. Maintenance of a functional higher order chromatin structure: the role of the nuclear matrix in normal and disease states. Gene Ther Mol Biol 2009;13:231-43.

[12] Hetzer MW, Wente SR. Border control at the nucleus: biogenesis and organization of the nuclear membrane and pore complexes. Dev Cell 2009; 17:606-16.

[13] Mika S, Rost B, NMPdb:. Database of nuclear matrix proteins. Nucleic Acids Res 2005:33:D160-3.

[14] Albrethsen J, Knol JC, Jimenez CR. Unravelling the nuclear matrix proteome. Proteomics 2009;72:71-81.

[15] Ishii K, Hirano Y, Araki N, Oda T, Kumeta M, Takeyasu K, et al. Nuclear matrix contains novel WD-repeat and disordered-region-rich proteins. FEBS Lett 2008;582:3515-9.

[16] Kolb T, Maass K, Hergt M, Aebi U, Herrmann H. Lamin A and lamin C form homodimers and coexist in higher complex forms both in the nucleoplasmic fraction and in the lamina of cultured human cells. Nucleus 2011;2:425-33.

[17] Radulescu AE, Cleveland DW. NuMA after 30 years: the matrix revisited. Trends Cell Biol 2010;20:214-22.

[18] Dingova H, Fukalova J, Maninova M, Philimonenko VV, Hozak P. Ultrastructural localization of actin and actin-binding proteins in the nucleus. Histochem Cell Biol 2009;131:425-34.

[19] Castano E, Philimonenko VV, Kahle M, Fukalova J, Kalendova A, Yildirim S, et al. Actin complexes in the cell nucleus: new stones in an old field. Histochem Cell Biol 2010;133:607-26.

[20] Zhong Z, Wilson KL, Dahl KN. Beyond lamins other structural components of the nucleoskeleton. Methods Cell Biol 2010;98:97-119.

[21] Simon DN, Wilson KL. Partners and post-translational modifications of nuclear lamins. Chromosoma 2013;122:13-31.

[22] Simon DN, Zastrow MS, Wilson KL. Direct actin binding to A- and B-type lamin tails and actin filament bundling by the lamin A tail. Nucleus 2010;1:264-72.

[23] Nakayasu H, Berezney R. Nuclear matrins: identification of the major nuclea matrix proteins. Proc Natl Acad Sci USA 1991:88:10312-6.

[24] Inagaki H, Matsushima Y, Nakamura K, Ohshima M, Kadowaki T, Kitagawa Y. A large DNA-binding nuclear protein with RNA recognition motif and serine/arginine-rich domain. J Biol Chem 1996;271:12525-31.

[25] Mortillaro MJ, Berezney R. Matrin CYP, an SR-rich cyclophilin that associates with the nuclear matrix and splicing factors. J Biol Chem 1998;273:8183-92.

[26] Kim SJ, Yoo BC, Uhm CS, Lee SW. Posttranslational arginine methylation of lamin A/C during myoblast fusion. Biochim Biophys Acta 2011:1814:308-17.

[27] Lin F, Worman HJ. Structural organization of the human gene encoding nuclear lamin A and nuclear lamin C. J Biol Chem 1993;268:16321-6.

[28] Dechat T, Pfleghaar K, Sengupta K, Shimi T, Shumaker DK, Solimando L, et al. Nuclear lamins: major factors in the structural organization and function of the nucleus and chromatin. Genes Dev 2008;22:832-53.

[29] Bonne G. http://www.umd.be/LMNA/.

[30] Alsheimer M, von Glasenapp E, Schnolzer M, Heid H, Benavente R. Meiotic lamin C2: the unique amino-terminal hexapeptide GNAEGR is essential for nuclear envelope association. Proc Natl Acad Sci USA 2000;97:13120-5.

[31] Jahn D, Schramm S, Benavente R, Alsheimer M. Dynamic properties of meiosis-specific lamin C2 and its impact on nuclear envelope integrity. Nucleus 2010;1:273-83.

[32] Dechat T, Gesson K, Foisner R. Lamina-independent lamins in the nuclear interior serve important functions. Cold Spring Harb Symp Quant Biol 2010;75:533-43.

[33] Dittmer TA, Misteli T. The lamin protein family. Genome Biol 2011;12:222

[34] Lund T, Svindland A, Pepaj M, Jensen AB, Berg JP, Kilhovd B, et al. Fibrin(ogen) may be an important target for methylglyoxal-derived AGE modification in elastic arteries of humans. Diabetes Vasc Dis Res 2011;8:284-94.

[35] Ferraro A, Eufemi M, Cervoni L, Marinetti R, Turano C. Glycosylated forms of nuclear lamins. FEBS Lett 1989:257:241-6.

[36] Wang J, Torii M, Liu H, Hart GW, Hu ZZ. dbOGAP - an integrated bioinformatics resource for protein O-GlcNAcylation. BMC Bioinform 2011;12:91

[37] Hahne H, Moghaddas Gholami A, Kuster B. Discovery of O-GlcNAc-modified proteins in published large-scale proteome data. Mol Cell Proteomics 2012;11:843-50.

[38] Hyder CL, Isoniemi KO, Torvaldson ES, Eriksson JE. Insights into intermediate filament regulation from development to ageing. J Cell Sci 2011:124:1363-72.

[39] Drougat L, Olivier-Van Stichelen S, Mortuaire M, Foulquier F, Lacoste AS, Michalski JC, et al. Characterization of O-GlcNAc cycling and proteomic identification of differentially O-GlcNAcylated proteins during G1/S transition. Biochim Biophys Acta 2012;1820:1839-48.

[40] Chen JT, Ho CW, Chi LM, Chien KY, Hsieh YJ, Lin SJ, et al. Identification of the lamin A/C phosphoepitope recognized by the antibody P-STM in mitotic HeLa S3 cells. BMC Biochem 2013:14:18.

[41] Kuga T, Nozaki N, Matsushita K, Nomura F, Tomonaga T. Phosphorylation statuses at different residues of lamin B2, B1, and A/C dynamically and independently change throughout the cell cycle. Exp Cell Res 2010;316:2301-12.

[42] Cenni V, Bertacchini J, Beretti F, Lattanzi G, Bavelloni A, Riccio M, et al. Ser404 is a nuclear target of Akt phosphorylation in C2C12 cells. J Proteome Res 2008; 7:4727-35

[43] Bertacchini J, Beretti F, Cenni V, Guida M, Gibellini F, Mediani L, et al. The protein kinase Akt/PKB regulates both prelamin A degradation and Lmna gene expression. FASEB J 2013;27:2145-55.

[44] Choudhary C, Kumar C, Gnad F, Nielsen ML, Rehman M, Walther TC, et al. Lysine acetylation targets protein complexes and co-regulates major cellular functions. Science 2009;325:834-40. 
[45] Reyes-Turcu FE, Ventii KH, Wilkinson KD. Regulation and cellular roles of ubiquitin-specific deubiquitinating enzymes. Annu Rev Biochem 2009;78:363-97.

[46] Savulescu AF, Shorer H, Kleifeld O, Cohen I, Gruber R, Glickman MH, et al. Nuclear import of an intact preassembled proteasome particle. Mol Biol Cell 2011;22:880-91.

[47] Braun S, Madhani HD. Shaping the landscape: mechanistic consequences of ubiquitin modification of chromatin. EMBO Rep 2012;13:619-30.

[48] Heun P. SUMOrganization of the nucleus. Curr Opin Cell Biol 2007;19: $350-5$.

[49] Gareau JR, Lima CD. The SUMO pathway: emerging mechanisms that shape specificity, conjugation and recognition. Nat Rev Mol Cell Biol 2010;11:861-71.

[50] Kolli N, Mikolajczyk J, Drag M, Mukhopadhyay D, Moffatt N, Dasso M, et al. Distribution and paralogue specificity of mammalian deSUMOylating enzymes. Biochem J 2010;430:335-44.

[51] Kim W, Bennett Eric J, Huttlin Edward L, Guo A, Li J, Possemato A, et al. Systematic and quantitative assessment of the ubiquitin-modified proteome. Mol Cell 2011;44:325-40.

[52] Cattin M-E, Bertrand AT, Schlossarek S, Le Bihan M-C, Skov Jensen S, Neuber C, et al. Heterozygous LmnadelK32 mice develop dilated cardiomyopathy through a combined pathomechanism of haploinsufficiency and peptide toxicity. Hum Mol Genet 2013;22:3152-64.

[53] Parnaik VK, Chaturvedi P, Muralikrishna B. Lamins, laminopathies and disease mechanisms: possible role for proteasomal degradation of key regulatory proteins. J Biosci 2011;36:471-9.

[54] Muralikrishna B, Chaturvedi P, Sinha K, Parnaik VK. Lamin misexpression upregulates three distinct ubiquitin ligase systems that degrade ATR kinase in HeLa cells. Mol Cell Biochem 2012;365:323-32.

[55] Blomster HA, Hietakangas V, Wu J, Kouvonen P, Hautaniemi S, Sistonen L. Novel proteomics strategy brings insight into the prevalence of SUMO-2 target sites. Mol Cell Proteomics 2009;8:1382-90.

[56] Matic I, Schimmel J, Hendriks IA, van Santen MA, van de Rijke F, van Dam H, et al. Site-specific identification of SUMO-2 targets in cells reveals an inverted SUMOylation motif and a hydrophobic cluster SUMOylation motif. Mol Cell 2010;39:641-52.

[57] Da Silva-Ferrada E, Lopitz-Otsoa F, Lang V, Rodriguez MS, Matthiesen R. Strategies to identify recognition signals and targets of SUMOylation. Biochem Res Int 2012;2012:16.

[58] Matic I, van Hagen M, Schimmel J, Macek B, Ogg SC, Tatham MH, et al. In vivo identification of human small ubiquitin-like modifier polymerization sites by high accuracy mass spectrometry and an in vitro to in vivo strategy. Mol Cell Proteomics 2008; 7:132-44.

[59] Wilkinson KA, Henley JM. Mechanisms, regulation and consequences of protein SUMOylation. Biochem J 2010;428:133-45.

[60] Zhang YQ, Sarge KD. Sumoylation regulates lamin A function and is lost in lamin A mutants associated with familial cardiomyopathies. J Cell Biol 2008; $182: 35-9$

[61] Sarge KD, Park-Sarge OK. Sumoylation and human disease pathogenesis. Trends Biochem Sci 2009;34:200-5.

[62] Boudreau E, Labib S, Bertrand AT, Decostre V, Bolongo PM, Sylvius N, et al. Lamin A/C mutants disturb sumo1 localization and sumoylation in vitro and in vivo. PLoS ONE 2012; 7:e45918.

[63] Simon DN, Domaradzki T, Hofmann WA, Wilson KL. Lamin A tail modification by SUMO1 is disrupted by familial partial lipodystrophy-causing mutations. Mol Biol Cell 2013;24:342-50.

[64] Ho CY, Lammerding J. Lamins at a glance. J Cell Sci 2012;125:2087-93.

[65] Vaughan OA, Alvarez-Reyes M, Bridger JM, Broers JLV, Ramaekers FCS, Wehnert $\mathrm{M}$, et al. Both emerin and lamin $\mathrm{C}$ depend on lamin $\mathrm{A}$ for localization at the nuclear envelope. J Cell Sci 2001;114:2577-90.

[66] Sullivan T, Escalante-Alcalde D, Bhatt H, Anver M, Bhat N, Nagashima K, et al. Loss of a-type lamin expression compromises nuclear envelope integrity leading to muscular dystrophy. J Cell Biol 1999;147:913-20.

[67] Saksena S, Summers MD, Burks JK, Johnson AE, Braunagel SC. Importin-alpha16 is a translocon-associated protein involved in sorting membrane proteins to the nuclear envelope. Nat Struct Mol Biol 2006;13:500-8.

[68] Antonin W, Ungricht R, Kutay U. Traversing the NPC along the pore membrane: targeting of membrane proteins to the INM. Nucleus 2011;2:87-91.

[69] Adam SA, Goldman RD. Insights into the differences between the A- and Btype nuclear lamins. Adv Biol Regul 2012;52:108-13.

[70] Wilson KL, Foisner R. Lamin-binding proteins. Cold Spring Harb Perspect Biol 2010;2:a000554.

[71] Al-Haboubi T, Shumaker DK, Koser J, Wehnert M, Fahrenkrog B. Distinct association of the nuclear pore protein Nup153 with A- and B-type lamins. Nucleus $2011 ; 2: 500-9$

[72] Gerace L, Huber MD. Nuclear lamina at the crossroads of the cytoplasm and nucleus. J Struct Biol 2012;177:24-31.

[73] Hozak P, Sasseville AM, Raymond Y, Cook PR. Lamin proteins form an internal nucleoskeleton as well as a peripheral lamina in human cells. J Cell Sci 1995; 108:635-44.

[74] Shimi T, Pfleghaar K, Kojima S, Pack CG, Solovei I, Goldman AE, et al. The Aand B-type nuclear lamin networks: microdomains involved in chromatin organization and transcription. Genes Dev 2008;22:3409-21.

[75] Broers JL, Machiels BM, van Eys GJ, Kuijpers HJ, Manders EM, van Driel R, et al. Dynamics of the nuclear lamina as monitored by GFP-tagged A-type lamins. J Cell Sci 1999;112:3463-75.
[76] Martin C, Chen S, Maya-Mendoza A, Lovric J, Sims PF, Jackson DA. Lamin B1 maintains the functional plasticity of nucleoli. J Cell Sci 2009;122:1551-62.

[77] Fricker M, Hollinshead M, White N, Vaux D. Interphase nuclei of many mammalian cell types contain deep, dynamic, tubular membrane-bound invaginations of the nuclear envelope. J Cell Biol 1997;136:531-44.

[78] Lee RK, Lui PP, Ngan EK, Lui JC, Suen YK, Chan F, et al. The nuclear tubular invaginations are dynamic structures inside the nucleus of HeLa cells. Can J Physiol Pharmacol 2006;84:477-86.

[79] Malhas A, Goulbourne C, Vaux DJ. The nucleoplasmic reticulum: form and function. Trends Cell Biol 2011;21:362-73.

[80] Ralle T, Grund C, Franke WW, Stick R. Intranuclear membrane structure formations by CaaX-containing nuclear proteins. J Cell Sci 2004;117:6095-104.

[81] Linde N, Stick R. Intranuclear membranes induced by lipidated proteins are derived from the nuclear envelope. Nucleus 2010;1:343-53.

[82] Goulbourne CN, Malhas AN, Vaux DJ. The induction of a nucleoplasmic reticulum by prelamin A accumulation requires CTP:phosphocholine cytidylyltransferase-alpha. J Cell Sci 2011;124:4253-66.

[83] Prufert K, Vogel A, Krohne G. The lamin CxxM motif promotes nuclear membrane growth. J Cell Sci 2004;117:6105-16.

[84] Polychronidou M, Grobhans J. Determining nuclear shape: the role of farnesylated nuclear membrane proteins. Nucleus 2011:2:17-23.

[85] Varela I, Pereira S, Ugalde AP, Navarro CL, Suarez MF, Cau P, et al. Combined treatment with statins and aminobisphosphonates extends longevity in a mouse model of human premature aging. Nat Med 2008;14:767-72.

[86] Herbomel P. Spinning nuclei in the brain of the zebrafish embryo. Curr Biol 1999;9:R627-8.

[87] Ji JY, Lee RT, Vergnes L, Fong LG, Stewart CL, Reue K, et al. Cell nuclei spin in the absence of lamin b1. J Biol Chem 2007;282:20015-26.

[88] Levy JR, Holzbaur EL. Dynein drives nuclear rotation during forward progression of motile fibroblasts. J Cell Sci 2008;121:3187-95.

[89] Wilson MH, Holzbaur EL. Opposing microtubule motors drive robust nuclear dynamics in developing muscle cells. J Cell Sci 2012;125:4158-69.

[90] Burke B, Ellenberg J. Remodelling the walls of the nucleus. Nat Rev Mol Cell Biol 2002;3:487-97.

[91] Gerlitz G, Reiner O, Bustin M. Microtubule dynamics alter the interphase nucleus. Cell Mol Life Sci: CMLS 2013;70:1255-68.

[92] Starr DA, Fridolfsson HN. Interactions between nuclei and the cytoskeleton are mediated by SUN-KASH nuclear-envelope bridges. Annu Rev Cell Dev Biol 2010;26:421-44.

[93] Cadot B, Gache V, Vasyutina E, Falcone S, Birchmeier C, Gomes ER. Nuclear movement during myotube formation is microtubule and dynein dependent and is regulated by Cdc42, Par6 and Par3. EMBO Rep 2012;13:741-9.

[94] Salpingidou G, Smertenko A, Hausmanowa-Petrucewicz I, Hussey PJ, Hutchison CJ. A novel role for the nuclear membrane protein emerin in association of the centrosome to the outer nuclear membrane. J Cell Biol 2007;178: 897-904.

[95] Chang W, Folker ES, Worman HJ, Gundersen GG. Emerin organizes actin flow for nuclear movement and centrosome orientation in migrating fibroblasts. Mol Biol Cell 2013;24:3869-80.

[96] Luxton GW, Gomes ER, Folker ES, Worman HJ, Gundersen GG. TAN lines: a novel nuclear envelope structure involved in nuclear positioning. Nucleus 2011;2:173-81

[97] Trivedi N, Solecki DJ. Neuronal migration illuminated: a look under the hood of the living neuron. Cell Adh Migr 2011;5:42-7.

[98] Evsyukova I, Plestant C, Anton ES. Integrative mechanisms of oriented neuronal migration in the developing brain. Annu Rev Cell Dev Biol 2013;29:299-353.

[99] Coffinier C, Chang SY, Nobumori C, Tu Y, Farber EA, Toth JI, et al. Abnormal development of the cerebral cortex and cerebellum in the setting of lamin B2 deficiency. Proc Natl Acad Sci USA 2010;107:5076-81.

[100] Yoon Byung C, Jung H, Dwivedy A, O'Hare Catherine M, Zivraj Krishna H, Holt Christine E. Local translation of extranuclear lamin b promotes axon maintenance. Cell 2012;148:752-64.

[101] Andres V, Gonzalez JM. Role of A-type lamins in signaling, transcription, and chromatin organization. J Cell Biol 2009;187:945-57.

[102] Chattopadhyay S, Pavithra L. MARs and MARBPs: key modulators of gene regulation and disease manifestation. Subcell Biochem 2007;41:213-30.

[103] Wang TY, Han ZM, Chai YR, Zhang JH. A mini review of MAR-binding proteins. Mol Biol Rep 2010;37:3553-60.

[104] de Lanerolle P, Serebryannyy L. Nuclear actin and myosins: life without filaments. Nat Cell Biol 2011;13:1282-8.

[105] Wilson RHC, Coverley D. Relationship between DNA replication and the nuclear matrix. Genes Cells 2013;18:17-31.

[106] Sanchez-Alvarez M, Sanchez-Hernandez N, Sune C. Spatial organization and dynamics of transcription elongation and pre-mRNA processing in live cells. Genet Res Int 2011;2011:626081.

[107] Melnik S, Deng B, Papantonis A, Baboo S, Carr IM, Cook PR. The proteomes of transcription factories containing RNA polymerases I, II or III. Nat Methods 2011;8:963-8.

[108] Salton M, Elkon R, Borodina T, Davydov A, Yaspo ML, Halperin E, et al. Matrin 3 binds and stabilizes mRNA. PLoS ONE 2011:6:e23882.

[109] Redwood AB, Perkins SM, Vanderwaal RP, Feng Z, Biehl KJ, Gonzalez-Suarez $\mathrm{I}$, et al. A dual role for A-type lamins in DNA double-strand break repair. Cell Cycle 2011;10:2549-60.

[110] Butin-Israeli V, Adam SA, Goldman RD. Regulation of nucleotide excision repair by nuclear lamin b1. PLoS ONE 2013;8:e69169. 
[111] Mahen R, Hattori H, Lee M, Sharma P, Jeyasekharan AD, Venkitaraman AR. A-type lamins maintain the positional stability of DNA damage repair foci in mammalian nuclei. PLoS ONE 2013;8:e61893.

[112] Salton M, Lerenthal Y, Wang S-Y, Chen DJ, Shiloh Y. Involvement of Matrin 3 and SFPQ/NONO in the DNA damage response. Cell Cycle 2010;9:1568-76.

[113] Ohata H, Miyazaki M, Otomo R, Matsushima-Hibiya Y, Otsubo C, Nagase T, et al. NuMA is required for the selective induction of p53 target genes. Mol Cell Biol 2013;33:2447-57.

[114] Endo A, Moyori A, Kobayashi A, Wong RW. Nuclear mitotic apparatus protein, NuMA, modulates p53-mediated transcription in cancer cells. Cell Death Dis 2013:4:e713.

[115] Bickmore WA, van Steensel B. Genome architecture: domain organization of interphase chromosomes. Cell 2013;152:1270-84.

[116] Hubner MR, Spector DL. Chromatin dynamics. Annu Rev Biophys 2010;39:471-89.

[117] Linnemann AK, Platts AE, Krawetz SA. Differential nuclear scaffold/matrix attachment marks expressed genes. Hum Mol Genet 2009;18:645-54.

[118] Elcock LS, Bridger JM. Exploring the relationship between interphase gene positioning, transcriptional regulation and the nuclear matrix. Biochem Soc Trans 2010;38:263-7.

[119] Hou C, Corces VG. Throwing transcription for a loop: expression of the genome in the 3D nucleus. Chromosoma 2012;121:107-16.

[120] Merkenschlager M, Odom DT. CTCF and cohesin: linking gene regulatory elements with their targets. Cell 2013;152:1285-97.

[121] Van Bortle K, Corces VG. Nuclear organization and genome function. Annu Rev Cell Dev Biol 2012;28:163-87.

[122] Wilson RH, Coverley D. Relationship between DNA replication and the nuclear matrix. Genes Cells 2013:18:17-31.

[123] Cavalli G, Misteli T. Functional implications of genome topology. Nat Struct Mol Biol 2013;20:290-9.

[124] Bolzer A, Kreth G, Solovei I, Koehler D, Saracoglu K, Fauth C, et al. Threedimensional maps of all chromosomes in human male fibroblast nuclei and prometaphase rosettes. PLoS Biol 2005;3:e157.

[125] Guelen L, Pagie L, Brasset E, Meuleman W, Faza MB, Talhout W, et al. Domain organization of human chromosomes revealed by mapping of nuclear lamina interactions. Nature 2008;453:948-51.

[126] Shevelyov YY, Nurminsky DI. The nuclear lamina as a gene-silencing hub. Curr Issues Mol Biol 2012;14:27-38.

[127] Mekhail K, Moazed D. The nuclear envelope in genome organization, expression and stability. Nat Rev Mol Cell Biol 2010;11:317-28.

[128] Bank EM, Gruenbaum Y. The nuclear lamina and heterochromatin: a complex relationship. Biochem Soc Trans 2011;39:1705-9.

[129] Van Bortle K, Corces VG. Spinning the web of cell fate. Cell 2013;152:1213-7.

[130] Lelievre SA. Contributions of extracellular matrix signaling and tissue architecture to nuclear mechanisms and spatial organization of gene expression control. Biochim Biophys Acta 2009;1790:925-35.

[131] Lelievre SA, Weaver VM, Nickerson JA, Larabell CA, Bhaumik A, Petersen OW, et al. Tissue phenotype depends on reciprocal interactions between the extracellular matrix and the structural organization of the nucleus. Proc Natl Acad Sci USA 1998;95:14711-6.

[132] Martins RP, Finan JD, Guilak F, Lee DA. Mechanical regulation of nuclear structure and function. Annu Rev Biomed Eng 2012;14:431-55.

[133] Swift J, Ivanovska IL, Buxboim A. Harada T, Dingal PCDP, Pinter J, et al. Nuclear lamin-A scales with tissue stiffness and enhances matrix-directed differentiation. Science 2013;341:1240104.

[134] Vidi PA, Chandramouly G, Gray M, Wang L, Liu E, Kim JJ, et al. Interconnected contribution of tissue morphogenesis and the nuclear protein NuMA to the DNA damage response. J Cell Sci 2012;125:350-61.

[135] Yu CE, Oshima J, Fu YH, Wijsman EM, Hisama F, Alisch R, et al. Positional cloning of the Werner's syndrome gene. Science 1996;272:258-62.

[136] Ellis NA, Groden J, Ye TZ, Straughen J, Lennon DJ, Ciocci S, et al. The Bloom's syndrome gene product is homologous to RecQ helicases. Cell 1995;83:655-66.

[137] Kitao S, Shimamoto A, Goto M, Miller RW, Smithson WA, Lindor NM, et al. Mutations in RECQL4 cause a subset of cases of Rothmund-Thomson syndrome. Nat Genet 1999;22:82-4.

[138] Colella S, Nardo T, Mallery D, Borrone C, Ricci R, Ruffa G, et al. Alterations in the CSB gene in three Italian patients with the severe form of Cockayne syndrome (CS) but without clinical photosensitivity. Hum Mol Genet 1999;8: 935-41.

[139] Henning KA, Li L, Iyer N, McDaniel LD, Reagan MS, Legerski R, et al. The Cockayne syndrome group A gene encodes a WD repeat protein that interacts with CSB protein and a subunit of RNA polymerase II TFIIH. Cell 1995;82: 555-64.

[140] Tanaka K, Miura N, Satokata I, Miyamoto I, Yoshida MC, Satoh Y, et al. Analysis of a human DNA excision repair gene involved in group A xeroderma pigmentosum and containing a zinc-finger domain. Nature 1990:348:73-6.

[141] De Sandre-Giovannoli A, Bernard R, Cau P, Navarro C, Amiel J, Boccaccio I, et al. Lamin A truncation in Hutchinson-Gilford progeria. Science 2003;300:2055.

[142] Eriksson M, Brown WT, Gordon LB, Glynn MW, Singer J, Scott L, et al. Recurrent de novo point mutations in lamin A cause Hutchinson-Gilford progeria syndrome. Nature 2003;423:293-8.

[143] Navarro CL, Cadinanos J, De Sandre-Giovannoli A, Bernard R, Courrier S, Boccaccio I, et al. Loss of ZMPSTE24 (FACE-1) causes autosomal recessive restrictive dermopathy and accumulation of Lamin A precursors. Hum Mol Genet 2005;14:1503-13.
[144] Navarro CL, De Sandre-Giovannoli A, Bernard R, Boccaccio I, Boyer A, Genevieve D, et al. Lamin A and ZMPSTE24 (FACE-1) defects cause nuclear disorganization and identify restrictive dermopathy as a lethal neonatal laminopathy. Hum Mol Genet 2004:13:2493-503.

[145] Puente XS, Quesada V, Osorio FG, Cabanillas R, Cadinanos J, Fraile JM, et al. Exome sequencing and functional analysis identifies BANF1 mutation as the cause of a hereditary progeroid syndrome. Am J Hum Genet 2011;88:650-6.

[146] Trifunovic A, Wredenberg A, Falkenberg M, Spelbrink JN, Rovio AT, Bruder $\mathrm{CE}$, et al. Premature ageing in mice expressing defective mitochondrial DNA polymerase. Nature 2004;429:417-23.

[147] Tyner SD, Venkatachalam S, Choi J, Jones S, Ghebranious N, Igelmann H, et al p53 mutant mice that display early ageing-associated phenotypes. Nature 2002;415:45-53

[148] Hasty P, Campisi J, Hoeijmakers J, van Steeg H, Vijg J. Aging and genome maintenance: lessons from the mouse? Science 2003;299:1355-9.

[149] Kipling D, Davis T, Ostler EL, Faragher RG. What can progeroid syndromes tel us about human aging? Science 2004;305:1426-31.

[150] Bokenkamp R, Raz V, Venema A, DeRuiter MC, van Munsteren C, Olive M, et al. Differential temporal and spatial progerin expression during closure of the ductus arteriosus in neonates. PLoS ONE 2011;6:e23975.

[151] McClintock D, Ratner D, Lokuge M, Owens DM, Gordon LB, Collins FS, et al The mutant form of lamin A that causes Hutchinson-Gilford progeria is biomarker of cellular aging in human skin. PLoS ONE 2007;2:e1269.

[152] Scaffidi P, Misteli T. Lamin A-dependent nuclear defects in human aging. Science 2006;312:1059-63.

[153] Olive M, Harten I, Mitchell R, Beers JK, Djabali K, Cao K, et al. Cardiovascular pathology in Hutchinson-Gilford progeria: correlation with the vascular pathology of aging. Arterioscler Thromb Vasc Biol 2010;30:2301-9.

[154] Agarwal AK, Fryns JP, Auchus RJ, Garg A. Zinc metalloproteinase, ZMPSTE24, is mutated in mandibuloacral dysplasia. Hum Mol Genet 2003;12:1995-2001.

[155] Hennekam RC. Hutchinson-Gilford progeria syndrome: review of the phenotype. Am J Med Genet A 2006;140:2603-24.

[156] Merideth MA, Gordon LB, Clauss S, Sachdev V, Smith AC, Perry MB, et al. Phenotype and course of Hutchinson-Gilford progeria syndrome. N Engl J Med 2008;358:592-604.

[157] Pereira S, Bourgeois P, Navarro C, Esteves-Vieira V, Cau P, De SandreGiovannoli A, et al. HGPS and related premature aging disorders: from genomic identification to the first therapeutic approaches. Mech Ageing Dev 2008:129:449-59.

[158] Gordon LB, McCarten KM, Giobbie-Hurder A, Machan JT, Campbell SE, Berns $\mathrm{SD}$, et al. Disease progression in Hutchinson-Gilford progeria syndrome: impact on growth and development. Pediatrics 2007;120:824-33.

[159] Feingold M, Kidd R. Progeria and scleroderma in infancy. Am J Dis Child 1971;122:61-2.

[160] Jimbow K, Kobayashi H, Ishii M, Oyanagi A, Ooshima A. Scar and keloidlike lesions in progeria. An electron-microscopic and immunohistochemical study. Arch Dermatol 1988;124:1261-6.

[161] Ackerman J, Gilbert-Barness E. Hutchinson-Gilford progeria syndrome: a pathologic study. Pediatr Pathol Mol Med 2002;21:1-13.

[162] Capell BC, Collins FS, Nabel EG. Mechanisms of cardiovascular disease in accelerated aging syndromes. Circul Res 2007;101:13-26.

[163] DeBusk FL. The Hutchinson-Gilford progeria syndrome. Report of 4 cases and review of the literature. J Pediatr 1972;80:697-724.

[164] Ishii T. Progeria: autopsy report of one case, with a review of pathologic findings reported in the literature. J Am Geriatr Soc 1976;24:193-202.

[165] Novelli G, Muchir A, Sangiuolo F, Helbling-Leclerc A, D’Apice MR, Massart C et al. Mandibuloacral dysplasia is caused by a mutation in LMNA-encoding lamin A/C. Am J Hum Genet 2002;71:426-31.

[166] Nijsten TE, De Moor A, Colpaert CG, Robert K, Mahieu LM, Lambert J. Restrictive dermopathy: a case report and a critical review of all hypotheses of its origin. Pediatr Dermatol 2002;19:67-72.

[167] Smitt JH, van Asperen CJ, Niessen CM, Beemer FA, van Essen AJ, Hulsmans RF, et al. Restrictive dermopathy. Report of 12 cases. Dutch Task Force on Genodermatology. Arch Dermatol 1998;134:577-9.

[168] Wesche WA, Cutlan RT, Khare V, Chesney T, Shanklin D. Restrictive dermopathy: report of a case and review of the literature. J Cutan Pathol 2001:28:211-8.

[169] Verloes A, Mulliez N, Gonzales M, Laloux F, Hermanns-Le T, Pierard GE, et al. Restrictive dermopathy, a lethal form of arthrogryposis multiplex with skin and bone dysplasias: three new cases and review of the literature. Am J Med Genet 1992:43:539-47.

[170] Witt DR, Hayden MR, Holbrook KA, Dale BA, Baldwin VJ, Taylor GP. Restrictive dermopathy: a newly recognized autosomal recessive skin dysplasia. Am J Med Genet 1986;24:631-48.

[171] Navarro CL, Esteves-Vieira V, Courrier S, Boyer A, Duong Nguyen T, Huong LT, et al. New ZMPSTE24 (FACE1) mutations in patients affected with restrictive dermopathy or related progeroid syndromes and mutation update. Eur J Hum Genet 2013.

[172] Ben Yaou R, Navarro C, Quijano-Roy S, Bertrand AT, Massart C, De SandreGiovannoli A, et al. Type B mandibuloacral dysplasia with congenita myopathy due to homozygous ZMPSTE24 missense mutation. Eur J Hum Genet 2011;19:647-54

[173] Hisama FM, Lessel D, Leistritz D, Friedrich K, McBride KL, Pastore MT, et al Coronary artery disease in a Werner syndrome-like form of progeria characterized by low levels of progerin, a splice variant of lamin A. Am J Med Genet A 2011;155A:3002-6. 
[174] Fukuchi K, Katsuya T, Sugimoto K, Kuremura M, Kim HD, Li L, et al. LMNA mutation in a 45 year old Japanese subject with Hutchinson-Gilford progeria syndrome. J Med Genet 2004;41:e67.

[175] Shalev SA, De Sandre-Giovannoli A, Shani AA, Levy N. An association of Hutchinson-Gilford progeria and malignancy. Am J Med Genet A 2007; 143A:1821-6.

[176] Moulson CL, Fong LG, Gardner JM, Farber EA, Go G, Passariello A, et al. Increased progerin expression associated with unusual LMNA mutations causes severe progeroid syndromes. Hum Mutat 2007;28:882-9.

[177] Doubaj Y, De Sandre-Giovannoli A, Vera E-V, Navarro CL, Elalaoui SC, Tajir M, et al. An inherited LMNA gene mutation in atypical Progeria syndrome. Am J Med Genet A 2012;158A:2881-7.

[178] Garg A, Subramanyam L, Agarwal AK, Simha V, Levine B, D’Apice MR, et al. Atypical Progeroid syndrome due to heterozygous missense LMNA mutations. J Clin Endocrinol Metab 2009;94:4971-83.

[179] Kane MS, Lindsay ME, Judge DP, Barrowman J, Ap Rhys C, Simonson L, et al. LMNA-associated cardiocutaneous progeria: an inherited autosoma dominant premature aging syndrome with late onset. Am J Med Genet A 2013;161:1599-611.

[180] Cabanillas R, Cadiñanos J, Villameytide JAF, Pérez M, Longo J, Richard JM, et al. Néstor-Guillermo progeria syndrome: a novel premature aging condition with early onset and chronic development caused by BANF1 mutations. Am J Med Genet A 2011;155:2617-25

[181] Knoch J, Kamenisch Y, Kubisch C, Berneburg M. Rare hereditary diseases with defects in DNA-repair. Eur J Dermatol 2012;22:443-55.

[182] Singh DK, Ghosh AK, Croteau DL, Bohr VA. RecQ helicases in DNA double strand break repair and telomere maintenance. Mutat Res 2012;736: $15-24$

[183] Lauper JM, Krause A, Vaughan TL, Monnat Jr RJ. Spectrum and risk of neoplasia in Werner syndrome: a systematic review. PLoS ONE 2013;8:e59709.

[184] Chu WK, Hickson ID. RecQ helicases: multifunctional genome caretakers. Nat Rev Cancer 2009:9:644-54.

[185] Ellis NA, German J. Molecular genetics of Bloom's syndrome. Hum Mol Genet 1996;5(Spec No):1457-63

[186] Langland G, Elliott J, Li Y, Creaney J, Dixon K, Groden J. The BLM helicase is necessary for normal DNA double-strand break repair. Cancer Res 2002;62:2766-70.

[187] Manthei KA, Keck JL. The BLM dissolvasome in DNA replication and repair Cell Mol Life Sci: CMLS 2013;70:4067-84.

[188] Bahr A, De Graeve F, Kedinger C, Chatton B. Point mutations causing Bloom's syndrome abolish ATPase and DNA helicase activities of the BLM protein. Oncogene 1998:17:2565-71.

[189] Croteau DL, Singh DK, Hoh Ferrarelli L, Lu H, Bohr VA. RECQL4 in genomic instability and aging. Trends Genet 2012;28:624-31.

[190] Larizza L, Roversi G, Volpi L. Rothmund-Thomson syndrome. Orphanet J Rare Dis 2010;5:2.

[191] Giglia-Mari G, Coin F, Ranish JA, Hoogstraten D, Theil A, Wijgers N, et al A new, tenth subunit of TFIIH is responsible for the DNA repair syndrome trichothiodystrophy group A. Nat Genet 2004;36:714-9.

[192] Egly JM, Coin F. A history of TFIIH: two decades of molecular biology on a pivotal transcription/repair factor. DNA Repair 2011;10:714-21.

[193] Morice-Picard F, Cario-Andre M, Rezvani H, Lacombe D, Sarasin A, Taieb A New clinico-genetic classification of trichothiodystrophy. Am J Med Genet A 2009;149A:2020-30

[194] Aamann MD, Muftuoglu M, Bohr VA, Stevnsner T. Multiple interaction partners for Cockayne syndrome proteins: implications for genome and transcriptome maintenance. Mech Ageing Dev 2013;134:212-24.

[195] Kamenisch Y, Berneburg M. Mitochondrial CSA and CSB: protein interactions and protection from ageing associated DNA mutations. Mech Ageing Dev 2013;134:270-4.

[196] Kraemer KH, Patronas NJ, Schiffmann R, Brooks BP, Tamura D, DiGiovanna JJ. Xeroderma pigmentosum, trichothiodystrophy and Cockayne syndrome: a complex genotype-phenotype relationship. Neuroscience 2007; $145: 1388-96$

[197] Hanawalt PC, Spivak G. Transcription-coupled DNA repair: two decades of progress and surprises. Nat Rev Mol Cell Biol 2008;9:958-70.

[198] Cleaver JE. Cancer in xeroderma pigmentosum and related disorders of DNA repair. Nat Rev Cancer 2005;5:564-73.

[199] Bradford PT, Goldstein AM, Tamura D, Khan SG, Ueda T, Boyle J, et al. Cancer and neurologic degeneration in xeroderma pigmentosum: long term followup characterises the role of DNA repair. J Med Genet 2011;48:168-76.

[200] Lehmann AR, McGibbon D, Stefanini M. Xeroderma pigmentosum. Orphanet J Rare Dis 2011;6:70.

[201] DiGiovanna JJ, Kraemer KH. Shining a light on xeroderma pigmentosum. J Invest Dermatol 2012;132:785-96.

[202] Gonzalez-Suarez I, Redwood AB, Perkins SM, Vermolen B, Lichtensztejin D, Grotsky DA, et al. Novel roles for A-type lamins in telomere biology and the DNA damage response pathway. EMBO J 2009;28:2414-27.

[203] Takeuchi H, Runger TM, Longwave UV. Light induces the aging-associated progerin. J Invest Dermatol 2013;133:1857-62.

[204] Derheimer FA, Kastan MB. Multiple roles of ATM in monitoring and maintaining DNA integrity. FEBS Lett 2010;584:3675-81.

[205] Anheim M, Tranchant C, Koenig M. The autosomal recessive cerebellar ataxias. N Engl J Med 2012;366:636-46.

[206] Neubauer S, Arutyunyan R, Stumm M, Dork T, Bendix R, Bremer M, et al. Radiosensitivity of ataxia telangiectasia and Nijmegen breakage syndrome homozygotes and heterozygotes as determined by three-color FISH chromosome painting. Radiat Res 2002;157:312-21.

[207] Lopez-Otin C, Blasco MA, Partridge L, Serrano M, Kroemer G. The hallmarks of aging. Cell 2013:153:1194-217.

[208] Burtner CR, Kennedy BK. Progeria syndromes and ageing: what is the connection? Nat Rev Mol Cell Biol 2010;11:567-78

[209] Zuela N, Bar DZ, Gruenbaum Y. Lamins in development, tissue maintenance and stress. EMBO Rep 2012;13:1070-8.

[210] Qin Z, Kalinowski A, Dahl KN, Buehler MJ. Structure and stability of the lamin A tail domain and HGPS mutant. J Struct Biol 2011;175:425-33.

[211] Delbarre E, Tramier M, Coppey-Moisan M, Gaillard C, Courvalin J-C, Buendia B. The truncated prelamin A in Hutchinson-Gilford progeria syndrome alters segregation of A-type and B-type lamin homopolymers. Hum Mol Genet 2006:15:1113-22.

[212] Goldman RD, Shumaker DK, Erdos MR, Eriksson M, Goldman AE, Gordon LB, et al. Accumulation of mutant lamin A causes progressive changes in nuclear architecture in Hutchinson-Gilford progeria syndrome. Proc Natl Acad Sc USA 2004:101:8963-8.

[213] Walters AD, Bommakanti A, Cohen-Fix O. Shaping the nucleus: factors and forces. J Cell Biochem 2012;113:2813-21.

[214] Heessen S, Fornerod M. The inner nuclear envelope as a transcription factor resting place. EMBO Rep 2007;8:914-9.

[215] Prokocimer M, Barkan R, Gruenbaum Y. Hutchinson-Gilford progeria syndrome through the lens of transcription. Aging Cell 2013;15:12070.

[216] Roux KJ, Kim DI, Raida M, Burke B. A promiscuous biotin ligase fusion protein identifies proximal and interacting proteins in mammalian cells. J Cell Biol 2012;196:801-10.

[217] Busch A, Kiel T, Heupel WM, Wehnert M, Hubner S. Nuclear protein import is reduced in cells expressing nuclear envelopathy-causing lamin A mutants. Exp Cell Res 2009;315:2373-85.

[218] Kelley JB, Datta S, Snow CJ, Chatterjee M, Ni L, Spencer A, et al. The defective nuclear lamina in Hutchinson-gilford progeria syndrome disrupts the nucleocytoplasmic Ran gradient and inhibits nuclear localization of Ubc9. Mol Cell Biol 2011;31:3378-95.

[219] Snow CJ, Dar A, Dutta A, Kehlenbach RH, Paschal BM. Defective nuclear import of Tpr in Progeria reflects the Ran sensitivity of large cargo transport. J Cell Biol 2013;201:541-57.

[220] Liu Y, Rusinol A, Sinensky M, Wang Y, Zou Y. DNA damage responses in progeroid syndromes arise from defective maturation of prelamin A. J Cell Sci 2006;119:4644-9.

[221] Rajanala K, Nandicoori VK. Localization of nucleoporin Tpr to the nuclear pore complex is essential for Tpr mediated regulation of the export of unspliced RNA. PLOS ONE 2012;7:e29921.

[222] Umlauf D, Bonnet J, Waharte F, Fournier M, Stierle M, Fischer B, et al. The human TREX-2 complex is stably associated with the nuclear pore basket. Cell Sci 2013:126:2656-67.

[223] Capelson M, Doucet C, Hetzer MW. Nuclear pore complexes: guardians of the nuclear genome. Cold Spring Harb Symp Quant Biol 2010;75:585-97.

[224] Liang Y, Hetzer MW. Functional interactions between nucleoporins and chromatin. Curr Opin Cell Biol 2011;23:65-70.

[225] Krull S, Dorries J, Boysen B, Reidenbach S, Magnius L, Norder H, et al. Protein $\mathrm{Tpr}$ is required for establishing nuclear pore-associated zones of heterochromatin exclusion. EMBO J 2010;29:1659-73.

[226] De Vos WH, Houben F, Kamps M, Malhas A, Verheyen F, Cox J, et al. Repetitive disruptions of the nuclear envelope invoke temporary loss of cellular compartmentalization in laminopathies. Hum Mol Genet 2011;20:4175-86.

[227] Dialynas G, Flannery KM, Zirbel LN, Nagy PL, Mathews KD, Moore SA, et al. LMNA variants cause cytoplasmic distribution of nuclear pore proteins in Drosophila and human muscle. Hum Mol Genet 2012;21:1544-56.

[228] de Noronha CM, Sherman MP, Lin HW, Cavrois MV, Moir RD, Goldman RD, et al. Dynamic disruptions in nuclear envelope architecture and integrity induced by HIV-1 Vpr. Science 2001;294:1105-8.

[229] Strunze S, Engelke Martin F, Wang IH, Puntener D, Boucke K, Schleich S, et al. Kinesin-1-mediated capsid disassembly and disruption of the nuclear pore complex promote virus infection. Cell Host Microbe 2011;10:210-23.

[230] Burke B, Stewart CL. The nuclear lamins: flexibility in function. Nat Rev Mo Cell Biol 2013;14:13-24.

[231] Hampoelz B, Lecuit T. Nuclear mechanics in differentiation and development. Curr Opin Cell Biol 2011;23:668-75

[232] Zwerger M, Ho CY, Lammerding J. Nuclear mechanics in disease. Annu Rev Biomed Eng 2011:13:397-428.

[233] Butin-Israeli V, Adam SA, Goldman AE, Goldman RD. Nuclear lamin functions and disease. Trends Genet 2012;28:464-71.

[234] de las Heras JI, Batrakou DG, Schirmer EC. Cancer biology and the nuclear envelope: a convoluted relationship. Semin Cancer Biol 2013;23:125-37.

[235] Cohen S, Au S, Pante N. How viruses access the nucleus. Biochim Biophys Acta 2011;1813:1634-45

[236] Lammerding J, Hsiao J, Schulze PC, Kozlov S, Stewart CL, Lee RT. Abnorma nuclear shape and impaired mechanotransduction in emerin-deficient cells. J Cell Biol 2005;170:781-91.

[237] Dahl KN, Scaffidi P, Islam MF, Yodh AG, Wilson KL, Misteli T. Distinct structural and mechanical properties of the nuclear lamina in Hutchinson-Gilford progeria syndrome. Proc Natl Acad Sci USA 2006;103:10271-6.

[238] Verstraeten VL, Ji JY, Cummings KS, Lee RT, Lammerding J. Increased mechanosensitivity and nuclear stiffness in Hutchinson-Gilford progeria cells: effects of farnesyltransferase inhibitors. Aging Cell 2008;7:383-93. 
[239] Zwerger M, Jaalouk DE, Lombardi ML, Isermann P, Mauermann M, Dialynas $\mathrm{G}$, et al. Myopathic lamin mutations impair nuclear stability in cells and tissue and disrupt nucleo-cytoskeletal coupling. Hum Mol Genet 2013;22: 2335-49.

[240] Chen CY, Chi YH, Mutalif RA, Starost MF, Myers TG, Anderson SA, et al. Accumulation of the inner nuclear envelope protein Sun 1 is pathogenic in progeric and dystrophic laminopathies. Cell 2012;149:565-77.

[241] Hernandez L, Roux KJ, Wong ES, Mounkes LC, Mutalif R, Navasankari R, et al. Functional coupling between the extracellular matrix and nuclear lamina by Wnt signaling in progeria. Dev Cell 2010;19:413-25.

[242] Booth-Gauthier EA, Du V, Ghibaudo M, Rape AD, Dahl KN, Ladoux B. Hutchinson-Gilford progeria syndrome alters nuclear shape and reduces cell motility in three dimensional model substrates. Integr Biol (Camb) 2013:5:569-77.

[243] Abad PC, Lewis J, Mian IS, Knowles DW, Sturgis J, Badve S, et al. NuMA influences higher order chromatin organization in human mammary epithelium. Mol Biol Cell 2007;18:348-61.

[244] Clarke PR, Zhang C. Spatial and temporal coordination of mitosis by Ran GTPase. Nat Rev Mol Cell Biol 2008;9:464-77.

[245] Nakano H, Wang W, Hashizume C, Funasaka T, Sato H, Wong RW. Unexpected role of nucleoporins in coordination of cell cycle progression. Cell Cycle 2011;10:425-33.

[246] Royle SJ. Mitotic moonlighting functions for membrane trafficking proteins. Traffic 2011;12:791-8.

[247] Beaudouin J, Gerlich D, Daigle N, Eils R, Ellenberg J. Nuclear envelope breakdown proceeds by microtubule-induced tearing of the lamina. Cell 2002;108:83-96.

[248] Zheng Y. A membranous spindle matrix orchestrates cell division. Nat Rev Mol Cell Biol 2010;11:529-35.

[249] Ma L, Tsai MY, Wang S, Lu B, Chen R, Iii JR, et al. Requirement for Nudel and dynein for assembly of the lamin B spindle matrix. Nat Cell Biol 2009:11:247-56.

[250] Goodman B, Channels W, Qiu M, Iglesias P, Yang G, Zheng Y, et al. Lamin B counteracts the kinesin Eg5 to restrain spindle pole separation during spindle assembly. J Biol Chem 2010;285:35238-44.

[251] Scaffidi P, Misteli T. Reversal of the cellular phenotype in the premature aging disease Hutchinson-Gilford progeria syndrome. Nat Med 2005;11:440-5

[252] Freund A, Laberge R-M, Demaria M, Campisi J. Lamin B1 loss is a senescenceassociated biomarker. Mol Biol Cell 2012:23:2066-75.

[253] Dreesen O, Chojnowski A, Ong PF, Zhao TY, Common JE, Lunny D, et al. Lamin B1 fluctuations have differential effects on cellular proliferation and senescence. J Cell Biol 2013;200:605-17.

[254] Shimi T, Butin-Israeli V, Adam SA, Hamanaka RB, Goldman AE, Lucas CA, et al. The role of nuclear lamin B1 in cell proliferation and senescence. Genes Dev 2011;25:2579-93

[255] Cao K, Capell BC, Erdos MR, Djabali K, Collins FS. A lamin A protein isoform overexpressed in Hutchinson-Gilford progeria syndrome interferes with mitosis in progeria and normal cells. Proc Natl Acad Sci USA 2007; 104:4949-54

[256] Dechat T, Shimi T, Adam SA, Rusinol AE, Andres DA, Spielmann HP, et al Alterations in mitosis and cell cycle progression caused by a mutant lamin A known to accelerate human aging. Proc Natl Acad Sci USA 2007;104:4955-60.

[257] Pratt CH, Curtain M, Donahue LR, Shopland LS. Mitotic defects lead to pervasive aneuploidy and accompany loss of RB1 activity in mouse LmnaDhe dermal fibroblasts. PLoS ONE 2011;6:e18065.

[258] Johnson BR, Nitta RT, Frock RL, Mounkes L, Barbie DA, Stewart CL, et al. A-type lamins regulate retinoblastoma protein function by promoting subnuclear localization and preventing proteasomal degradation. Proc Natl Acad Sci USA 2004; 101:9677-82

[259] Nitta RT, Smith CL, Kennedy BK. Evidence that proteasome-dependent degradation of the retinoblastoma protein in cells lacking A-type lamins occurs independently of gankyrin and MDM2. PLoS ONE 2007;2:e963.

[260] Rodriguez J, Calvo F, Gonzalez JM, Casar B, Andres V, Crespo P. ERK1/2 MAP kinases promote cell cycle entry by rapid, kinase-independent disruption of retinoblastoma-lamin A complexes. J Cell Biol 2010;191:967-79.

[261] Pekovic V, Harborth J, Broers JL, Ramaekers FC, van Engelen B, Lammens M, et al. Nucleoplasmic LAP2alpha-lamin A complexes are required to maintain a proliferative state in human fibroblasts. J Cell Biol 2007;176:163-72.

[262] Marji J, O’Donoghue SI, McClintock D, Satagopam VP, Schneider R, Ratner $\mathrm{D}$, et al. Defective Lamin A-Rb signaling in Hutchinson-Gilford progeria syndrome and reversal by farnesyltransferase inhibition. PLoS ONE 2010;5:e11132.

[263] Manning AL, Longworth MS, Dyson NJ. Loss of pRB causes centromere dysfunction and chromosomal instability. Genes Dev 2010;24:1364-76.

[264] Gonzalez-Suarez I, Gonzalo S. Nurturing the genome: A-type lamins preserve genomic stability. Nucleus 2010;1:129-35

[265] Mehta IS, Eskiw CH, Arican HD, Kill IR, Bridger JM. Farnesyltransferase inhibitor treatment restores chromosome territory positions and active chromosome dynamics in Hutchinson-Gilford progeria syndrome cells. Genome Biol 2011;12:R74.

[266] Taimen P, Pfleghaar K, Shimi T, Moller D, Ben-Harush K, Erdos MR, et al. A progeria mutation reveals functions for lamin A in nuclear assembly, architecture, and chromosome organization. Proc Natl Acad Sci USA 2009;106:20788-93.

[267] McCord RP, Nazario-Toole A, Zhang H, Chines PS, Zhan Y, Erdos MR, et al. Correlated alterations in genome organization, histone methylation, and DNA-lamin A/C interactions in Hutchinson-Gilford progeria syndrome. Genome Res 2013;23:260-9.

[268] Shumaker DK, Dechat T, Kohlmaier A, Adam SA, Bozovsky MR, Erdos MR, et al Mutant nuclear lamin A leads to progressive alterations of epigenetic control in premature aging. Proc Natl Acad Sci USA 2006;103:8703-8.

[269] Montes de Oca R, Andreassen PR, Wilson KL. Barrier-to-autointegration factor influences specific histone modifications. Nucleus 2011;2:580-90.

[270] Montes de Oca R, Shoemaker CJ, Gucek M, Cole RN, Wilson KL. Barrier-toautointegration factor proteome reveals chromatin-regulatory partners. PLoS ONE 2009;4:e7050

[271] Heyn H, Moran S, Esteller M. Aberrant DNA methylation profiles in the premature aging disorders Hutchinson-Gilford progeria and Werner syndrome. Epigenetics 2013;8:28-33.

[272] Musich PR, Zou Y. DNA-damage accumulation and replicative arrest in Hutchinson-Gilford progeria syndrome. Biochem Soc Trans 2011;39:1764-9.

[273] Manju K, Muralikrishna B, Parnaik VK. Expression of disease-causing lamin A mutants impairs the formation of DNA repair foci. J Cell Sc 2006:119:2704-14.

[274] Schumacher B, Hoeijmakers JH, Garinis GA. Sealing the gap between nuclear DNA damage and longevity. Mol Cell Endocrinol 2009;299:112-7.

[275] Hutchison CJ. The role of DNA damage in laminopathy progeroid syndromes. Biochem Soc Trans 2011;39:1715-8.

[276] Richards SA, Muter J, Ritchie P, Lattanzi G, Hutchison CJ. The accumulation of un-repairable DNA damage in laminopathy progeria fibroblasts is caused by ROS generation and is prevented by treatment with $\mathrm{N}$-acetyl cysteine. Hum Mol Genet 2011;20:3997-4004.

[277] Liu B, Wang Z, Zhang L, Ghosh S, Zheng H, Zhou Z. Depleting the methyltransferase Suv39h1 improves DNA repair and extends lifespan in a progeria mouse model. Nat Commun 2013;4:1868.

[278] Swanson EC, Manning B, Zhang H, Lawrence JB. Higher-order unfolding of satellite heterochromatin is a consistent and early event in cell senescence. Cell Biol 2013:203:929-42.

[279] Chaturvedi P, Khanna R, Parnaik VK. Ubiquitin ligase RNF123 mediates degradation of heterochromatin protein 1alpha and beta in lamin A/C knock-down cells. PLoS ONE 2012;7:e47558.

[280] Chaturvedi P, Parnaik VK. Lamin A rod domain mutants target heterochromatin protein 1 alpha and beta for proteasomal degradation by activation of F-box protein, FBXW10. PLoS ONE 2010;5:e10620.

[281] Smith-Vikos T, Slack FJ. MicroRNAs and their roles in aging. J Cell Sc 2012;125:7-17.

[282] Liu FJ, Wen T, Liu L. MicroRNAs as a novel cellular senescence regulator. Ageing Res Rev 2012:11:41-50.

[283] Malhas A, Saunders NJ, Vaux DJ. The nuclear envelope can control gene expression and cell cycle progression via miRNA regulation. Cell Cycle 2010;9:531-9.

[284] Ugalde AP, Ramsay AJ, de la Rosa J, Varela I, Marino G, Cadinanos J, et al. Aging and chronic DNA damage response activate a regulatory pathway involving miR-29 and p53. EMBO J 2011;30:2219-32.

[285] Yu KR, Lee S, Jung JW, Hong IS, Kim HS, Seo Y, et al. MicroRNA-141-3p plays a role in human mesenchymal stem cell aging by directly targeting ZMPSTE24. J Cell Sci 2013;126:5422-31.

[286] Jung H-J, Coffinier C, Choe Y, Beigneux AP, Davies BSJ, Yang SH, et al. Regulation of prelamin A but not lamin C by miR-9, a brain-specific microRNA. Proc Natl Acad Sci USA 2012;109:E423-31.

[287] Nissan X, Blondel S, Navarro C, Maury Y, Denis C, Girard M, et al. Unique preservation of neural cells in Hutchinson-Gilford progeria syndrome is due to the expression of the neural-specific miR-9 MicroRNA. Cell Rep 2012;2:1-9.

[288] Arancio W, Giordano C, Pizzolanti G. A ceRNA analysis on LMNA gene focusing on the Hutchinson-Gilford progeria syndrome. J Clin Bioinform 2013;3:2.

[289] Sylvius N, Bonne G, Straatman K, Reddy T, Gant TW, Shackleton S. MicroRNA expression profiling in patients with lamin A/C-associated muscular dystrophy. FASEB J 2011;25:3966-78.

[290] Spector DL, Lamond AI. Nuclear speckles. Cold Spring Harbor Perspect Biol 2011:3:a000646.

[291] Daguenet E, Baguet A, Degot S, Schmidt U, Alpy F, Wendling C, et al. Perispeckles are major assembly sites for the exon junction core complex. Mol Biol Cel 2012:23:1765-82.

[292] Belin BJ, Cimini BA, Blackburn EH, Mullins RD. Visualization of actin filaments and monomers in somatic cell nuclei. Mol Biol Cell 2013;24:982-94.

[293] Tripathi V, Song DY, Zong X, Shevtsov SP, Hearn S, Fu XD, et al. SRSF1 regulates the assembly of pre-mRNA processing factors in nuclear speckles. Mol Biol Cell 2012;23:3694-706.

[294] Akef A, Zhang H, Masuda S, Palazzo AF. Trafficking of mRNAs containing ALREX-promoting elements through nuclear speckles. Nucleus 2013;4:326-40.

[295] Harries LW, Hernandez D, Henley W, Wood AR, Holly AC, Bradley-Smith RM et al. Human aging is characterized by focused changes in gene expression and deregulation of alternative splicing. Aging Cell 2011:10:868-78.

[296] Holly AC, Melzer D, Pilling LC, Fellows AC, Tanaka T, Ferrucci L, et al. Changes in splicing factor expression are associated with advancing age in man. Mech Ageing Dev 2013;134:356-66.

[297] Montecucco A, Biamonti G. Pre-mRNA processing factors meet the DNA damage response. Front Genet 2013;4:102.

[298] Tang Y, Horikawa I, Ajiro M, Robles AI, Fujita K, Mondal AM, et al. Downregulation of splicing factor SRSF3 induces p53beta, an alternatively spliced isoform of 553 that promotes cellular senescence. Oncogene 2013;32:2792-8. 
[299] Blanco FJ, Bernabeu C. The splicing factor SRSF1 as a marker for endothelial senescence. Front Physiol 2012;3:54.

[300] Saitoh N, Sakamoto C, Hagiwara M, Agredano-Moreno LT, Jimenez-Garcia LF, Nakao M. The distribution of phosphorylated SR proteins and alternative splicing are regulated by RANBP2. Mol Biol Cell 2012;23:1115-28.

[301] Lopez-Mejia IC, Vautrot V, De Toledo M, Behm-Ansmant I, Bourgeois CF, Navarro CL, et al. A conserved splicing mechanism of the LMNA gene controls premature aging. Hum Mol Genet 2011;20:4540-55.

[302] Luo YB, Mitrpant C, Johnsen RD, Fabian VA, Fletcher S, Mastaglia FL, et al. Investigation of age-related changes in LMNA splicing and expression of progerin in human skeletal muscles. Int J Clin Exp Pathol 2013:6:2778-86.

[303] van Leeuwen FW, de Kleijn DP, van den Hurk HH, Neubauer A, Sonnemans MA, Sluijs JA, et al. Frameshift mutants of beta amyloid precursor protein and ubiquitin-B in Alzheimer's and Down patients. Science 1998;279:242-7.

[304] Brulliard M, Lorphelin D, Collignon O, Lorphelin W, Thouvenot B, Gothie $\mathrm{E}$, et al. Nonrandom variations in human cancer ESTs indicate that mRNA heterogeneity increases during carcinogenesis. Proc Natl Acad Sci USA 2007:104:7522-7.

[305] Cao K, Blair CD, Faddah DA, Kieckhaefer JE, Olive M, Erdos MR, et al. Progerin and telomere dysfunction collaborate to trigger cellular senescence in normal human fibroblasts. J Clin Invest 2011;121:2833-44

[306] Wallis CV, Sheerin AN, Green MHL, Jones CJ, Kipling D, Faragher RGA. Fibroblast clones from patients with Hutchinson-Gilford progeria can senesce despite the presence of telomerase. Exp Gerontol 2004;39:461-7.

[307] Huang S, Risques RA, Martin GM, Rabinovitch PS, Oshima J. Accelerated telomere shortening and replicative senescence in human fibroblasts overexpressing mutant and wild-type lamin A. Exp Cell Res 2008;314:82-91.

[308] Benson EK, Lee SW, Aaronson SA. Role of progerin-induced telomere dysfunction in HGPS premature cellular senescence. J Cell Sci 2010;123:2605-12.

[309] Kudlow BA, Stanfel MN, Burtner CR, Johnston ED, Kennedy BK. Suppression of proliferative defects associated with processing-defective lamin A mutants by hTERT or inactivation of p53. Mol Biol Cell 2008;19:5238-48.

[310] Blasco MA. The epigenetic regulation of mammalian telomeres. Nat Rev Genet 2007;8:299-309.

[311] Raz V, Vermolen BJ, Garini Y, Onderwater JJM, Mommaas-Kienhuis MA, Koster AJ, et al. The nuclear lamina promotes telomere aggregation and centromere peripheral localization during senescence of human mesenchymal stem cells. J Cell Sci 2008;121:4018-28.

[312] De Vos WH, Houben F, Hoebe RA, Hennekam R, van Engelen B, Manders $\mathrm{EM}$, et al. Increased plasticity of the nuclear envelope and hypermobility of telomeres due to the loss of A-type lamins. Biochim Biophys Acta 2010; 1800:448-58.

[313] Barascu A, Le Chalony C, Pennarun G, Genet D, Zaarour N, Bertrand P. Oxydative stress alters nuclear shape through lamins dysregulation: a route to senescence. Nucleus 2012;3:411-7.

[314] Lattanzi G, Marmiroli S, Facchini A, Maraldi NM. Nuclear damages and oxidative stress: new perspectives for laminopathies. Eur J Histochem 2012;56: e45.

[315] Viteri G, Chung YW, Stadtman ER. Effect of progerin on the accumulation of oxidized proteins in fibroblasts from Hutchinson Gilford progeria patients. Mech Ageing Dev 2010;131:2-8.

[316] Sieprath T, Darwiche R, De Vos WH. Lamins as mediators of oxidative stress. Biochem Biophys Res Commun 2012:421:635-9.

[317] Singhapol C, Pal D, Czapiewski R, Porika M, Nelson G, Saretzki GC. Mitochondrial telomerase protects cancer cells from nuclear DNA damage and apoptosis. PLoS ONE 2013;8:e52989.

[318] Ahmed S, Passos JF, Birket MJ, Beckmann T, Brings S, Peters H, et al. Telomerase does not counteract telomere shortening but protects mitochondrial function under oxidative stress. J Cell Sci 2008;121:1046-53.

[319] Park JI, Venteicher AS, Hong JY, Choi J, Jun S, Shkreli M, et al. Telomerase modulates Wnt signalling by association with target gene chromatin. Nature 2009;460:66-72.

[320] Hoffmeyer K, Raggioli A, Rudloff S, Anton R, Hierholzer A, Del Valle I, et al. Wnt/ $\beta$-catenin signaling regulates telomerase in stem cells and cancer cells. Science 2012;336:1549-54.

[321] Sahin E, Colla S, Liesa M, Moslehi J, Muller FL, Guo M, et al. Telomere dysfunction induces metabolic and mitochondrial compromise. Nature 2011;470:359-65.

[322] Rufini A, Tucci P, Celardo I, Melino G. Senescence and aging: the critical roles of p53. Oncogene 2013;32:5129-43.

[323] Moiseeva O, Bourdeau V, Vernier M, Dabauvalle MC, Ferbeyre G. Retinoblastoma-independent regulation of cell proliferation and senescence by the p53-p21 axis in lamin A/C-depleted cells. Aging Cell 2011;10:789-97.

[324] Varela I, Cadinanos J, Pendas AM, Gutierrez-Fernandez A, Folgueras AR, Sanchez LM, et al. Accelerated ageing in mice deficient in Zmpste24 protease is linked to p53 signalling activation. Nature 2005;437:564-8.

[325] Tanikawa C, Espinosa M, Suzuki A, Masuda K, Yamamoto K, Tsuchiya E, et al. Regulation of histone modification and chromatin structure by the p53-PADI4 pathway. Nat Commun 2012;3:676.

[326] Rahman-Roblick R, Roblick UJ, Hellman U, Conrotto P, Liu T, Becker S, et al. p53 targets identified by protein expression profiling. Proc Natl Acad Sci USA 2007; 104:5401-6.

[327] Korfali N, Srsen V, Waterfall M, Batrakou DG, Pekovic V, Hutchison CJ, et al. A flow cytometry-based screen of nuclear envelope transmembrane proteins identifies NET4/Tmem53 as involved in stress-dependent cell cycle withdrawal. PLoS ONE 2011;6:e18762.
[328] Lin CP, Choi YJ, Hicks GG, He L. The emerging functions of the p53-miRNA network in stem cell biology. Cell Cycle 2012;11:2063-72.

[329] Raver-Shapira N, Marciano E, Meiri E, Spector Y, Rosenfeld N, Moskovits N, et al. Transcriptional activation of miR-34a contributes to p53-mediated apoptosis. Mol Cell 2007;26:731-43.

[330] Chang TC, Wentzel EA, Kent OA, Ramachandran K, Mullendore M, Lee KH, et al. Transactivation of miR-34a by p53 broadly influences gene expression and promotes apoptosis. Mol Cell 2007;26:745-52.

[331] Tazawa H, Tsuchiya N, Izumiya M, Nakagama H. Tumor-suppressive miR34a induces senescence-like growth arrest through modulation of the E2F pathway in human colon cancer cells. Proc Natl Acad Sci USA 2007;104: $15472-7$

[332] Boominathan L. The tumor suppressors p53, p63, and p73 are regulators of microRNA processing complex. PLoS ONE 2010;5:e10615.

[333] Osorio FG, Ugalde AP, Marino G, Puente XS, Freije JM, Lopez-Otin C. Cell autonomous and systemic factors in progeria development. Biochem Soc Trans 2011;39:1710-4.

[334] Wan G, Zhang X, Langley RR, Liu Y, Hu X, Han C, et al. DNA-damage-induced nuclear export of precursor microRNAs is regulated by the ATM-AKT pathway. Cell Rep 2013;3:2100-12.

[335] Ma YS, Wu SB, Lee WY, Cheng JS, Wei YH. Response to the increase of oxidative stress and mutation of mitochondrial DNA in aging. Biochim Biophys Acta 2009;1790:1021-9.

[336] Murphy MP. How mitochondria produce reactive oxygen species. Biochem J 2009;417:1-13.

[337] Sena Laura A, Chandel Navdeep S. Physiological roles of mitochondrial reactive oxygen species. Mol Cell 2012;48:158-67.

[338] Pagliarini DJ, Calvo SE, Chang B, Sheth SA, Vafai SB, Ong S-E, et al. A Mitochondrial protein compendium elucidates complex I disease biology. Cell 2008; 134:112-23.

[339] Lanza IR, Nair KS. Mitochondrial function as a determinant of life span. Pflugers Arch Eur J Physiol 2010;459:277-89.

[340] Gomes Ana P, Price Nathan L, Ling Alvin JY, Moslehi Javid J, Montgomery MK, Rajman L, et al. Declining NAD+ induces a pseudohypoxic state disrupting nuclear-mitochondrial communication during aging. Cell 2013;155:1624-38.

[341] Caron M, Auclair M, Donadille B, Bereziat V, Guerci B, Laville M, et al. Human lipodystrophies linked to mutations in A-type lamins and to HIV protease inhibitor therapy are both associated with prelamin A accumulation, oxidative stress and premature cellular senescence. Cell Death Differ 2007;14:1759-67.

[342] Peinado JR, Quiros PM, Pulido MR, Marino G, Martinez-Chantar ML, VazquezMartinez R, et al. Proteomic profiling of adipose tissue from Zmpste24-1mice, a model of lipodystrophy and premature aging, reveals major changes in mitochondrial function and vimentin processing. Mol Cell Proteomics 2011;10. M111.008094.

[343] Rivera-Torres J, Acin-Perez R, Cabezas-Sanchez P, Osorio FG, GonzalezGomez C, Megias D, et al. Identification of mitochondrial dysfunction in Hutchinson-Gilford progeria syndrome through use of stable isotope labeling with amino acids in cell culture. J Proteomics 2013;91C:466-77.

[344] Pellegrino MW, Nargund AM, Haynes CM. Signaling the mitochondrial unfolded protein response. Biochim Biophys Acta 2013;1833:410-6.

[345] Houtkooper RH, Mouchiroud L, Ryu D, Moullan N, Katsyuba E, Knott G, et al. Mitonuclear protein imbalance as a conserved longevity mechanism. Nature 2013;497:451-7

[346] Walter P, Ron D. The unfolded protein response: from stress pathway to homeostatic regulation. Science 2011;334:1081-6.

[347] Bidault G, Garcia M, Vantyghem MC, Ducluzeau PH, Morichon R, Thiyagarajah $\mathrm{K}$, et al. Lipodystrophy-linked LMNA p.R482W mutation induces clinical early atherosclerosis and in vitro endothelial dysfunction. Arterioscler Thromb Vasc Biol 2013:33:2162-71.

[348] Fujimoto M, Hayashi T. New insights into the role of mitochondria-associated endoplasmic reticulum membrane. Int Rev Cell Mol Biol 2011;292:73-117.

[349] Hotamisligil GS. Endoplasmic reticulum stress and the inflammatory basis of metabolic disease. Cell 2010;140:900-17.

[350] Li N, Bates DJ, An J, Terry DA, Wang E. Up-regulation of key microRNAs, and inverse down-regulation of their predicted oxidative phosphorylation target genes, during aging in mouse brain. Neurobiol Aging 2011;32:944-55.

[351] Huang L, Mollet S, Souquere S, Le Roy F, Ernoult-Lange M, Pierron G, et al. Mitochondria associate with P-bodies and modulate microRNA-mediated RNA interference. J Biol Chem 2011;286:24219-30.

[352] Mowla SN, Perkins ND, Jat PS. Friend or foe: emerging role of nuclear factor kappa-light-chain-enhancer of activated B cells in cell senescence. Onco Targets Ther 2013;6:1221-9.

[353] Tilstra JS, Robinson AR, Wang J, Gregg SQ, Clauson CL, Reay DP, et al. NFkappaB inhibition delays DNA damage-induced senescence and aging in mice. J Clin Invest 2012;122:2601-12.

[354] Osorio FG, Barcena C, Soria-Valles C, Ramsay AJ, de Carlos F, Cobo J, et al Nuclear lamina defects cause ATM-dependent NF-kappaB activation and link accelerated aging to a systemic inflammatory response. Genes Dev 2012;26:2311-24.

[355] Chien Y, Scuoppo C, Wang X, Fang X, Balgley B, Bolden JE, et al. Control of the senescence-associated secretory phenotype by NF-kappaB promotes senescence and enhances chemosensitivity. Genes Dev 2011;25:2125-36.

[356] Salminen A, Kauppinen A, Kaarniranta K. Emerging role of NF-kappaB signaling in the induction of senescence-associated secretory phenotype (SASP). Cell Signal 2012;24:835-45. 
[357] Acosta JC, Banito A, Wuestefeld T, Georgilis A, Janich P, Morton JP, et al. A complex secretory program orchestrated by the inflammasome controls paracrine senescence. Nat Cell Biol 2013;15:978-90.

[358] Ragnauth CD, Warren DT, Liu Y, McNair R, Tajsic T, Figg N, et al. Prelamin A acts to accelerate smooth muscle cell senescence and is a novel biomarker of human vascular aging. Circulation 2010;121:2200-10.

[359] Liu Y, Drozdov I, Shroff R, Beltran LE, Shanahan CM. Prelamin A accelerates vascular calcification via activation of the DNA damage response and senescence-associated secretory phenotype in vascular smooth muscle cells. Circul Res 2013;112:e99-109.

[360] Olivieri F, Rippo MR, Monsurro V, Salvioli S, Capri M, Procopio AD, et al. MicroRNAs linking inflamm-aging, cellular senescence and cancer. Ageing Res Rev 2013;12:1056-68.

[361] Hergenreider E, Heydt S, Treguer K, Boettger T, Horrevoets AJG, Zeiher AM, et al. Atheroprotective communication between endothelial cells and smooth muscle cells through miRNAs. Nat Cell Biol 2012;14:249-56.

[362] van Balkom BW, de Jong OG, Smits M, Brummelman J, den Ouden K, de Bree PM, et al. Endothelial cells require miR-214 to secrete exosomes that suppress senescence and induce angiogenesis in human and mouse endothelial cells. Blood 2013;121:3997-4006. S1-15.

[363] Weilner S, Schraml E, Redl H, Grillari-Voglauer R, Grillari J. Secretion of microvesicular miRNAs in cellular and organismal aging. Exp Gerontol 2013;48:626-33.

[364] Wenzel V, Roedl D, Gabriel D, Gordon LB, Herlyn M, Schneider R, et al. Naive adult stem cells from patients with Hutchinson-Gilford progeria syndrome express low levels of progerin in vivo. Biol Open 2012;1:516-26.

[365] Espada J, Varela I, Flores I, Ugalde AP, Cadinanos J, Pendas AM, et al. Nuclear envelope defects cause stem cell dysfunction in premature-aging mice. J Cell Biol 2008:181:27-35.

[366] Scaffidi P, Misteli T. Lamin A-dependent misregulation of adult stem cells associated with accelerated ageing. Nat Cell Biol 2008;10:452-9.

[367] Fu Y, Huang B, Shi Z, Han J, Wang Y, Huangfu J, et al. SRSF1 and SRSF9 RNA binding proteins promote Wnt signalling-mediated tumorigenesis by enhancing beta-catenin biosynthesis. EMBO Mol Med 2013;5:737-50.

[368] Lavasani M, Robinson AR, Lu A, Song M, Feduska JM, Ahani B, et al. Musclederived stem/progenitor cell dysfunction limits healthspan and lifespan in a murine progeria model. Nat Commun 2012;3:608.

[369] Song M, Lavasani M, Thompson SD, Lu A, Ahani B, Huard J. Muscle-derived stem/progenitor cell dysfunction in Zmpste24-deficient progeroid mice limits muscle regeneration. Stem Cell Res Ther 2013;4:33.

[370] Ciechanover A. Intracellular protein degradation: from a vague idea through the lysosome and the ubiquitin-proteasome system and onto human diseases and drug targeting. Bioorg Med Chem 2013;21:3400-10.

[371] Romisch K. Endoplasmic reticulum-associated degradation. Annu Rev Cell Dev Biol 2005;21:435-56

[372] Baraibar MA, Friguet B. Changes of the proteasomal system during the aging process. Prog Mol Biol Transl Sci 2012;109:249-75

[373] Tomaru U, Takahashi S, Ishizu A, Miyatake Y, Gohda A, Suzuki S, et al, Decreased proteasomal activity causes age-related phenotypes and promotes the development of metabolic abnormalities. Am J Pathol 2012;180: 963-72.

[374] Wirawan E, Vanden Berghe T, Lippens S, Agostinis P, Vandenabeele P. Autophagy: for better or for worse. Cell Res $2012 \cdot 22: 43-61$.

[375] Lee J, Giordano S, Zhang J. Autophagy, mitochondria and oxidative stress: cross-talk and redox signalling. Biochem J 2012;441:523-40.

[376] Nedelsky NB, Todd PK, Taylor JP. Autophagy and the ubiquitin-proteasome system: collaborators in neuroprotection. Biochim Biophys Acta 2008; 1782:691-9.

[377] Korolchuk VI, Menzies FM, Rubinsztein DC. Mechanisms of cross-talk between the ubiquitin-proteasome and autophagy-lysosome systems. FEBS Lett 2010;584:1393-8.

[378] Lee DY, Arnott D, Brown EJ. Ubiquilin4 is an adaptor protein that recruits Ubiquilin1 to the autophagy machinery. EMBO Rep 2013;14:373-81.

[379] Grosjean-Raillard J, Tailler M, Ades L, Perfettini JL, Fabre C, Braun T, et al. ATM mediates constitutive NF-kappaB activation in high-risk myelodysplastic syndrome and acute myeloid leukemia. Oncogene 2009;28:1099-109.

[380] Miyamoto S. Nuclear initiated NF-kappaB signaling: NEMO and ATM take center stage. Cell Res 2011;21:116-30.

[381] Dodson M, Darley-Usmar V, Zhang J. Cellular metabolic and autophagic pathways: traffic control by redox signaling. Free Radic Biol Med 2013;63:207-21.

[382] Tam AB, Mercado EL, Hoffmann A, Niwa M. ER stress activates NF-kappaB by integrating functions of basal IKK activity, IRE1 and PERK. PLoS ONE 2012;7:e45078.

[383] Alexia C, Poalas K, Carvalho G, Zemirli N, Dwyer J, Dubois SM, et al. The endoplasmic reticulum acts as a platform for ubiquitylated components of nuclear factor kappaB signaling. Sci Signal 2013;6:ra79.

[384] Nezis IP, Stenmark H. p62 at the interface of autophagy, oxidative stress signaling, and cancer. Antioxid Redox Signal 2012;17:786-93.

[385] Komatsu M, Kageyama S, Ichimura Y. p62/SQSTM1/A170: physiology and pathology. Pharmacol Res 2012;66:457-62.

[386] He LQ, Lu JH, Yue ZY. Autophagy in ageing and ageing-associated diseases. Acta Pharmacol Sin 2013;34:605-11.

[387] Kroemer G, Marino G, Levine B. Autophagy and the integrated stress response. Mol Cell 2010;40:280-93

[388] Salminen A, Kaarniranta K. Regulation of the aging process by autophagy. Trends Mol Med 2009;15:217-24.
[389] Vellai T. Autophagy genes and ageing. Cell Death Differ 2009;16:94-102

[390] Fullgrabe J, Klionsky DJ, Joseph B. The return of the nucleus: transcriptional and epigenetic control of autophagy. Nat Rev Mol Cell Biol 2014;15: 65-74.

[391] Kaushik S, Cuervo AM. Chaperone-mediated autophagy: a unique way to enter the lysosome world. Trends Cell Biol 2012;22:407-17.

[392] Rubinsztein DC, Marino G, Kroemer G. Autophagy and aging. Cell 2011;146:682-95

[393] Marino G, Ugalde AP, Salvador-Montoliu N, Varela I, Quiros PM, Cadinanos $J$, et al. Premature aging in mice activates a systemic metabolic response involving autophagy induction. Hum Mol Genet 2008;17:2196-211.

[394] Young SG, Fong LG, Michaelis S, Prelamin A. Zmpste24, misshapen cell nuclei, and progeria - new evidence suggesting that protein farnesylation could be important for disease pathogenesis. J Lipid Res 2005;46:2531-58.

[395] Basso AD, Kirschmeier P, Bishop WR. Thematic review series: lipid posttranslational modifications. Farnesyl transferase inhibitors. J Lipid Res 2006;47:15-31.

[396] Young SG, Meta M, Yang SH, Fong LG. Prelamin A farnesylation and progeroid syndromes. J Biol Chem 2006;281:39741-5.

[397] Young SG, Yang SH, Davies BS, Jung HJ, Fong LG. Targeting protein prenylation in progeria. Sci Transl Med 2013;5:171ps3.

[398] Gordon LB, Kleinman ME, Miller DT, Neuberg DS, Giobbie-Hurder A Gerhard-Herman M, et al. Clinical trial of a farnesyltransferase inhibitor in children with Hutchinson-Gilford progeria syndrome. Proc Natl Acad Sci USA 2012;109:16666-71.

[399] Couzin-Frankel J. Medicine. Drug trial offers uncertain start in race to save children with progeria. Science 2012;337:1594-5.

[400] Verstraeten VL, Peckham LA, Olive M, Capell BC, Collins FS, Nabel EG, et al. Protein farnesylation inhibitors cause donut-shaped cell nuclei attributable to a centrosome separation defect. Proc Natl Acad Sci USA 2011;108: 4997-5002.

[401] Rauch A, Thiel CT, Schindler D, Wick U, Crow YJ, Ekici AB, et al. Mutations in the pericentrin (PCNT) gene cause primordial dwarfism. Science 2008;319:816-9.

[402] Griffith E, Walker S, Martin CA, Vagnarelli P, Stiff T, Vernay B, et al. Mutations in pericentrin cause Seckel syndrome with defective ATR-dependent DNA damage signaling. Nat Genet 2008;40:232-6.

[403] Marcus AI, Zhou J, O’Brate A, Hamel E, Wong J, Nivens M, et al. The synergistic combination of the farnesyl transferase inhibitor lonafarnib and paclitaxe enhances tubulin acetylation and requires a functional tubulin deacetylase. Cancer Res 2005;65:3883-93

[404] Zhou J, Vos CC, Gjyrezi A, Yoshida M, Khuri FR, Tamanoi F, et al. The protein farnesyltransferase regulates HDAC6 activity in a microtubule-dependent manner. J Biol Chem 2009;284:9648-55.

[405] Hubbert C, Guardiola A, Shao R, Kawaguchi Y, Ito A, Nixon A, et al. HDAC6 is a microtubule-associated deacetylase. Nature 2002:417:455-8.

[406] Ding H, Dolan PJ, Johnson GV. Histone deacetylase 6 interacts with the microtubule-associated protein tau. J Neurochem 2008;106:2119-30.

[407] Zilberman Y, Ballestrem C, Carramusa L, Mazitschek R, Khochbin S, Bershadsky A. Regulation of microtubule dynamics by inhibition of the tubulin deacetylase HDAC6. J Cell Sci 2009;122:3531-41.

[408] Kovacs JJ, Hubbert C, Yao TP. The HDAC complex and cytoskeleton. Novartis Found Symp 2004:259:170-7, discussion 8-81, 223-5.

[409] Rusinol AE, Sinensky MS. Farnesylated lamins, progeroid syndromes and farnesyl transferase inhibitors. J Cell Sci 2006;119:3265-72.

[410] Whyte DB, Kirschmeier P, Hockenberry TN, Nunez-Oliva I, James L, Catino JJ, et al. K- and N-Ras are geranylgeranylated in cells treated with farnesy protein transferase inhibitors. J Biol Chem 1997;272:14459-64.

[411] Wasko BM, Dudakovic A, Hohl RJ. Bisphosphonates induce autophagy by depleting geranylgeranyl diphosphate. J Pharmacol Exp Ther 2011;337: 540-6.

[412] De Sandre-Giovannoli A, Sigaudy S, et al. Phase II open trial for Hutchinson-Gilford progeria syndrome: two years analysis associating pravastatin and zoledronic acid; 2014 (in preparation).

[413] Bifulco M, D’Alessandro A, Paladino S, Malfitano AM, Notarnicola M, Caruso MG, et al. N6-isopentenyladenosine improves nuclear shape in fibroblasts from humans with progeroid syndromes by inhibiting the farnesylation of prelamin A. FEBS J 2013;24:12544.

[414] Morcos PA, Li Y, Jiang S. Vivo-Morpholinos: a non-peptide transporte delivers Morpholinos into a wide array of mouse tissues. Biotechniques 2008;45:613-4, 6, 8 passim.

[415] Osorio FG, Navarro CL, Cadinanos J, Lopez-Mejia IC, Quiros PM, Bartoli C, et al. Splicing-directed therapy in a new mouse model of human accelerated aging. Sci Transl Med 2011;3:106ra7.

[416] Singh RK, Cooper TA. Pre-mRNA splicing in disease and therapeutics. Trends Mol Med 2012;18:472-82.

[417] Johnson SC, Rabinovitch PS, Kaeberlein M. mTOR is a key modulator of ageing and age-related disease. Nature 2013;493:338-45.

[418] Laplante M, Sabatini DM. mTOR signaling in growth control and disease. Cell 2012;149:274-93.

[419] Benjamin D, Colombi M, Moroni C, Hall MN. Rapamycin passes the torch: new generation of mTOR inhibitors. Nat Rev Drug Discov 2011;10:868-80.

[420] Zoncu R, Efeyan A, Sabatini DM. mTOR: from growth signal integration to cancer, diabetes and ageing. Nat Rev Mol Cell Biol 2011;12:21-35.

[421] Johnson SC, Martin GM, Rabinovitch PS, Kaeberlein M. Preserving youth: does rapamycin deliver? Sci Transl Med 2013;5:211fs40. 
[422] Jung CH, Ro SH, Cao J, Otto NM, Kim DH. mTOR regulation of autophagy. FEBS Lett 2010;584:1287-95.

[423] Madeo F, Tavernarakis N, Kroemer G. Can autophagy promote longevity? Nat Cell Biol 2010;12:842-6.

[424] Cao K, Graziotto JJ, Blair CD, Mazzulli JR, Erdos MR, Krainc D, et al. Rapamycin reverses cellular phenotypes and enhances mutant protein clearance in Hutchinson-Gilford progeria syndrome cells. Sci Transl Med 2011;3:89ra58.

[425] Ramos FJ, Chen SC, Garelick MG, Dai DF, Liao CY, Schreiber KH, et al. Rapamycin reverses elevated mTORC1 signaling in lamin A/C-deficient mice, rescues cardiac and skeletal muscle function, and extends survival. Sci Transl Med 2012;4:144ra03.

[426] Choi JC, Muchir A, Wu W, Iwata S, Homma S, Morrow JP, et al. Temsirolimus activates autophagy and ameliorates cardiomyopathy caused by lamin A/C gene mutation. Sci Transl Med 2012;4:144ra02.

[427] Cenni V, Capanni C, Columbaro M, Ortolani M, D’Apice MR, Novelli G, et al. Autophagic degradation of farnesylated prelamin $A$ as a therapeutic approach to lamin-linked progeria. Eur J Histochem 2011;55:e36.

[428] Lattanzi G, Ortolani M, Columbaro M, Prencipe S, Mattioli E, Lanzarini C, et al. Lamins are rapamycin targets that impact human longevity: a study in centenarians. J Cell Sci 2014;127:147-57.

[429] Saha B, Cypro A, Martin GM, Oshima J. Rapamycin decreases DNA damage accumulation and enhances cell growth of WRN deficient human fibroblasts. Aging Cell 2013;6:12190.

[430] Talaei F, van Praag VM, Henning RH. Hydrogen sulfide restores a normal morphological phenotype in Werner syndrome fibroblasts, attenuates oxidative damage and modulates mTOR pathway. Pharmacol Res 2013;74:34-44.

[431] Progeria Research Foundation. Newsletter 2011;(fall)

[432] Niessner H, Beck D, Sinnberg T, Lasithiotakis K, Maczey E, Gogel J, et al. The farnesyl transferase inhibitor lonafarnib inhibits mTOR signaling and enforces sorafenib-induced apoptosis in melanoma cells. J Invest Dermatol 2011;131:468-79.

[433] Avruch J, Long X, Lin Y, Ortiz-Vega S, Rapley J, Papageorgiou A, et al. Activation of mTORC1 in two steps: Rheb-GTP activation of catalytic function and increased binding of substrates to raptor. Biochem Soc Trans 2009;37:223-6.

[434] Hanker AB, Mitin N, Wilder RS, Henske EP, Tamanoi F, Cox AD, et al. Differential requirement of CAAX-mediated posttranslational processing for Rheb localization and signaling. Oncogene 2010;29:380-91.

[435] Jewell JL, Russell RC, Guan KL. Amino acid signalling upstream of mTOR. Nat Rev Mol Cell Biol 2013;14:133-9.

[436] Lee JY, Koga H, Kawaguchi Y, Tang W, Wong E, Gao YS, et al. HDAC6 controls autophagosome maturation essential for ubiquitin-selective quality-control autophagy. EMBO J 2010;29:969-80.

[437] Lamark T, Johansen T. Aggrephagy: selective disposal of protein aggregates by macroautophagy. Int J Cell Biol 2012;2012:736905.

[438] Morris BJ. Seven sirtuins for seven deadly diseases of aging. Free Radic Biol Med 2013;56:133-71.

[439] Kurosu H, Kuro OM. The Klotho gene family as a regulator of endocrine fibroblast growth factors. Mol Cell Endocrinol 2009;299:72-8.

[440] Russell SJ, Kahn CR. Endocrine regulation of ageing. Nat Rev Mol Cell Biol 2007;8:681-91.

[441] Houtkooper RH, Williams RW, Auwerx J. Metabolic networks of longevity. Cell 2010;142:9-14.

[442] Barzilai N, Huffman DM, Muzumdar RH, Bartke A. The critical role of metabolic pathways in aging. Diabetes 2012;61:1315-22.

[443] Cohen E, Dillin A. The insulin paradox: aging, proteotoxicity and neurodegeneration. Nat Rev Neurosci 2008;9:759-67.

[444] Vitale G, Salvioli S, Franceschi C. Oxidative stress and the ageing endocrine system. Nat Rev Endocrinol 2013;9:228-40.

[445] Vendelbo MH, Nair KS. Mitochondrial longevity pathways. Biochim Biophys Acta 2011;1813:634-44.

[446] Salminen A, Kaarniranta K. Insulin/IGF-1 paradox of aging: regulation via AKT/IKK/NF-kappaB signaling. Cell Signal 2010;22:573-7.

[447] Zhang G, Li J, Purkayastha S, Tang Y, Zhang H, Yin Y, et al. Hypothalamic programming of systemic ageing involving IKK- $\beta$, NF- $\kappa B$ and GnRH. Nature 2013;497:211-6.

[448] Marino G, Ugalde AP, Fernandez AF, Osorio FG, Fueyo A, Freije JM, et al. Insulinlike growth factor 1 treatment extends longevity in a mouse model of human premature aging by restoring somatotroph axis function. Proc Natl Acad Sci USA 2010;107:16268-73.

[449] Sinclair DA, Guarente L. Small-molecule allosteric activators of sirtuins. Annu Rev Pharmacol Toxicol 2013;16:16.

[450] Liu B, Ghosh S, Yang X, Zheng H, Liu X, Wang Z, et al. Resveratrol rescues SIRT1-dependent adult stem cell decline and alleviates progeroid features in laminopathy-based progeria. Cell Metab 2012;16:738-50.

[451] Ge Y, Chen J. Mammalian target of rapamycin (mTOR) signaling network in skeletal myogenesis. J Biol Chem 2012;287:43928-35.

[452] Liu G-H, Guan T, Datta K, Coppinger J, Yates J, Gerace L. Regulation of myoblast differentiation by the nuclear envelope protein NET39. Mol Cell Biol 2009;29:5800-12.

[453] Datta K, Guan T, Gerace L. NET37, a nuclear envelope transmembrane protein with glycosidase homology, is involved in myoblast differentiation. J Biol Chem 2009;284:29666-76.

[454] Siller R, Greenhough S, Park IH, Sullivan GJ. Modelling human disease with pluripotent stem cells. Curr Gene Ther 2013;13:99-110.

[455] Wu SM, Hochedlinger K. Harnessing the potential of induced pluripotent stem cells for regenerative medicine. Nat Cell Biol 2011;13:497-505.

[456] Cherry Anne BC, Daley George Q. Reprogramming cellular identity for regenerative medicine. Cell 2012;148:1110-22.

[457] Jang J, Yoo JE, Lee JA, Lee DR, Kim JY, Huh YJ, et al. Disease-specific induced pluripotent stem cells: a platform for human disease modeling and drug discovery. Exp Mol Med 2012;44:202-13.

[458] Onder TT, Daley GQ. New lessons learned from disease modeling with induced pluripotent stem cells. Curr Opin Genet Dev 2012;22:500-8.

[459] Ebert AD, Liang P, Wu JC. Induced pluripotent stem cells as a disease modeling and drug screening platform. J Cardiovasc Pharmacol 2012;60:408-16.

[460] Rajamohan D, Matsa E, Kalra S, Crutchley J, Patel A, George V, et al. Current status of drug screening and disease modelling in human pluripotent stem cells. Bioessays 2013;35:281-98.

[461] Liu GH, Barkho BZ, Ruiz S, Diep D, Qu J, Yang SL, et al. Recapitulation of premature ageing with iPSCs from Hutchinson-Gilford progeria syndrome. Nature 2011;472:221-5.

[462] Ho JC, Zhou T, Lai WH, Huang Y, Chan YC, Li X, et al. Generation of induced pluripotent stem cell lines from 3 distinct laminopathies bearing heterogeneous mutations in lamin A/C. Aging 2011;3:380-90.

[463] Liu GH, Suzuki K, Qu J, Sancho-Martinez I, Yi F, Li M, et al. Targeted gene correction of laminopathy-associated LMNA mutations in patient-specific iPSCs. Cell Stem Cell 2011;8:688-94

[464] Zuo B, Yang J, Wang F, Wang L, Yin Y, Dan J, et al. Influences of lamin A levels on induction of pluripotent stem cells. Biol Open 2012;1:1118-27.

[465] Zhang J, Lian Q, Zhu G, Zhou F, Sui L, Tan C, et al. A human iPSC model of Hutchinson-Gilford progeria reveals vascular smooth muscle and mesenchymal stem cell defects. Cell Stem Cell 2011;8:31-45.

[466] Siu CW, Lee YK, Ho JC, Lai WH, Chan YC, Ng KM, et al. Modeling of lamin A/C mutation premature cardiac aging using patient-specific induced pluripotent stem cells. Aging 2012;4:803-22.

[467] Xiong ZM, LaDana C, Wu D, Cao K. An inhibitory role of progerin in the gene induction network of adipocyte differentiation from iPS cells. Aging 2013;5:288-303.

[468] Miller JD, Ganat YM, Kishinevsky S, Bowman RL, Liu B, Tu EY, et al. Human iPSC-based modeling of late-onset disease via progerin-induced aging. Cell Stem Cell 2013;13:691-705.

[469] Kim E, Ambroziak P, Otto JC, Taylor B, Ashby M, Shannon K, et al. Disruption of the mouse Rce1 gene results in defective Ras processing and mislocalization of Ras within cells. J Biol Chem 1999;274:8383-90.

[470] Bergo MO, Leung GK, Ambroziak P, Otto JC, Casey PJ, Gomes AQ, et al. Isoprenylcysteine carboxyl methyltransferase deficiency in mice. J Biol Chem 2001;276:5841-5.

[471] Ibrahim MX, Sayin VI, Akula MK, Liu M, Fong LG, Young SG, et al. Targeting isoprenylcysteine methylation ameliorates disease in a mouse model of progeria. Science 2013;340:1330-3.

[472] de la Rosa J, Freije JMP, Cabanillas R, Osorio FG, Fraga MF, Fernández-García MS, et al. Prelamin A causes progeria through cell-extrinsic mechanisms and prevents cancer invasion. Nat Commun 2013;4:2268. 